\title{
Portfolio Reallocation and Exchange Rate Dynamics
}

\author{
Liang Ding \\ Jun Ma \\ Macalester College \\ University of Alabama \\ (ding@macalester.edu) \\ (jma@cba.ua.edu)
}

November 1, 2010

\begin{abstract}
This paper explains exchange rate dynamics by linking financial customers' foreign exchange order flow with their dynamic portfolio reallocation. For any currency pair in a particular period, one currency has higher assets return than the other and can be considered the high-return-currency (HRC). Financial institutions attempt to hold more HRC assets when they become more risk-loving or the relative return of the assets is expected to increase. Such a portfolio reallocation generates buy order toward the HRC and the currency appreciates. As the HRC changes over time, the direction that the relative return and risk appetite affect the exchange rate varies in different regimes.
\end{abstract}

JEL classification: F31; G11; G15 


\section{Introduction}

Explaining exchange rate dynamics has been the biggest challenge in international finance since the collapse of the Bretton Woods system. The early efforts started with macro-based models that tried to connect exchange rate dynamics with fundamental variables such as money supplies, aggregate outputs, and interest rates. However, as argued by Meese and Rogoff (1983), these macro-based models cannot even outperform a random walk and their explanatory power is minimal at best.

In response to these failures, a number of scholars have attempted to ground macro models in more solid microfoundations. Major advances along these lines include the dynamic general equilibrium model of Obstfeld and Rogoff (1995), the productivity differentials model of DeGregorio and Wolf (1994), and the behavioral equilibrium exchange rate model of Clark and MacDonald (1999). While a large number of studies have subsequently claimed to find success with various fundamentals-based models, the success has not proven to be robust. This pessimistic conclusion is shared by several comprehensive surveys including Lane (2001), Sarno and Taylor (2002), and Cheung, Chinn, and Pascual (2005).

The most recent attempts to improve the macro-based models emphasize expected fundamentals. Engel and West (2005) treat the exchange rate as an asset price and argue that the exchange rate should be the net present value of expected future fundamentals. Engel, Mark, and West (2007) further show that including expected fundamentals improves the performance of macro-based models. However, this improvement is only limited to certain currencies and long horizons (16-quarter and longer); unsatisfactory performance at short horizons continues to haunt macro models. ${ }^{1}$ One explanation for these disappointing results is that the relationship between the exchange rate and macro fundamentals is nonlinear and highly unstable. ${ }^{2}$ Current models that try to capture the nonlinearity, Bacchetta and Wincoop (2009) for instance, mainly rely on econometric techniques and do not provide explicit economic rationales for the structural change. Attributing the large amount ${ }^{3}$ of exchange rate volatility unexplained by macro-based models to "unobservable fundamentals", as suggested by Engel and West (2010), is far from satisfying.

Given the poor performance of the macro models, a new line of research developed in the

\footnotetext{
${ }^{1}$ where the "short horizons" correspond to any time horizon between a day and perhaps a year or two, depending on context.

${ }^{2}$ See survey (Cheung and Chinn 2001) and econometric evidence (Rossi (2005) and Sarno and Valente (2009)).

${ }^{3}$ Normally the explanatory power of the macro models is less than $10 \%$.
} 
mid-1990s that focused on the behavior of price-setting economic agents in foreign exchange markets - the FX dealers. The initial results of FX market microstructure research seemed stunning: Evans and Lyons (2002) show that order flow can explain 40-60 percent of daily exchange rate fluctuations. Despite its unprecedented explanatory power, these findings were initially criticized because they left unanswered the question of what drives order flow. Although reduced-form examinations such as Evans and Lyons $(2007,2008)$ show that order flow contains fundamental information, no transition mechanism is provided in these studies. ${ }^{4}$

FX orders are submitted by market participants. Intuitively, explaining the trading behavior of these participants would be a straightforward and reasonable approach to explain exchange rate dynamics. Evans and Lyons (2005) made the initial effort in this direction through the use of consumption-based utility functions, which we believe have difficulty in describing the behavior of highly leveraged financial institutions. Models in Carlson, Dahl, and Osler (2008) as well as Dunne, Hau, and Moore (2010) better accommodate market reality, but their solutions contain explanatory variables that are difficult to be measured explicitly and therefore lack direct empirical support. ${ }^{5}$ Moreover, these models say little about the regime-switches that apparently exist in exchange rate dynamics.

Motivated by the financial crisis in 2008, researchers have examined more specific features of market participants: Brunnermeier, Nagel, and Pedersen (2008) and Gagnon and Chaboud (2007) find that a popular FX arbitrage strategy - the carry trade - may play an important role in exchange rate determination, while Adrian, Etula, and Shin (2009) find a connection between exchange rates and risk appetite, arguing that high leverage is followed by appreciation of the USD. Supporting evidence presented by these studies, however, is either limited to certain currencies and periods, or obtained through panel data regression, which could hide inconsistencies across currencies and periods. Counterexamples to the mechanisms proposed in these papers are not hard to find ${ }^{6}$ and lead to concerns about whether the mechanisms are robust and the inconsistencies reconcilable.

In the big picture, pure econometric models can capture exchange rate dynamics to some extent but lack economic intuition, macro-based models are intuitive but lack adequate micro

\footnotetext{
${ }^{4}$ These studies do not show how market participants incorporate the fundamental information into their trading behavior, which essentially determines the order flow.

${ }^{5}$ The explanatory variables "expected future spot rate" and "belief change" proposed in Carlson, Dahl, and Osler (2008) and Dunne, Hau, and Moore (2010) respectively are difficult to measure, and these models were consequently unable to be tested directly.

${ }^{6}$ Details are presented in section 4 .
} 
foundation and decent explanatory power at short horizons, and microstructure models have a solid microfoundation and high explanatory power but need to better explain the origin of order flow. With the exception of order flow models, existing work has yet to produce models that are sufficiently statistically satisfactory to be considered reliable and robust. One model may do well for one exchange rate in one era, but not for another currency or another era. Although the order flow models seem to be robust across time and currencies, it is vital that we develop a better understanding of what drives order flow.

The goal of this paper is to propose an exchange rate model that has strong intuition, a solid microfoundation, and supporting evidence across currencies and periods. We start with several stylized facts about the FX market: the exchange rate is quoted by dealers based on the order flow they receive (Evans and Lyons (2002)); the order flow is dominated by inter-dealer and financial customer order flow (New York Federal Reserve Bank (2009)); and inter-dealer order flow is proportional to the non-public customer order flow (Evans and Lyons (2002)). Hence, exchange rate dynamics are mainly driven by the FX transactions initiated by financial customers. Consequently, a core question this paper tries to answer is what drives the financial customers to buy or sell in the FX market?

Financial customers are profit-seeking and attempt to maximize the return of their portfolios, which usually contain domestic and foreign assets. As market conditions change, portfolio reallocation between domestic and foreign assets produces FX order flows. Due to the differences in monetary policies and economic growth potential between the two countries, for each currency pair in a particular period, one currency has a higher expected return in bonds or stocks than the other and can be called the high-return-currency (HRC). When the relative return of HRC assets is expected to increase (decrease), financial customers attempt to hold more HRC assets, which generates positive (negative) order flow for the HRC, and the HRC appreciates (depreciates). Meanwhile, holding HRC assets is risky due to exchange rate risk and the higher volatility associated with HRC assets. As expected market risk increases, financial customers would hold fewer HRC assets, causing the HRC to depreciate. Holding relative return and market risk constant, when financial firms have higher (lower) risk appetite, they hold more (less) HRC assets and that currency appreciates (depreciates).

We test these theoretical implications with ample data and find country-specific and periodspecific supportive evidence for all major currencies throughout the sample period. At the 
1-month horizon, our model can explain on average $27 \%$ of the British Pound dynamics, ${ }^{7} 24 \%$ of the Canadian Dollar, 24\% of the Deutsche Mark, 13\% of the Euro and 14\% of the Japanese Yen. To our knowledge, these are the best results obtained at monthly horizon by a structural model without using order flow. The model also outperforms a random walk in the out-of-sample test.

Our paper follows the FX market microstructure literature in the sense that we model how market participants' behavior affects exchange rate dynamics. ${ }^{8}$ But instead of considering order flow as an exogenous variable, like most microstructure studies, we tie FX order flow to the endogenous portfolio flows which emerge under optimal dynamic portfolio allocation processes. Exchange rate dynamics are thus based directly on financial market structure as opposed to traditional macroeconomic variables. ${ }^{9}$ Furthermore, the way that financial variables drive the exchange rate varies in different regimes that constantly switch, and such a switch can be caused explicitly by the change of HRC status, the business cycle, or the dominance of conflicting assets reallocation. Our paper is not the first to explain exchange rate dynamics through market participants trading behavior, but it is the first among similar models to explicitly incorporate regime-switching and provide country-specific and period-specific supporting evidence from explicit ex ante tests.

The regime-switching mechanism proposed by our paper provides an economic rationale for nonlinearity in exchange rate models. We would emphasize that this mechanism is intuitive and explicit, which can improve the performance of pure econometric regime-switch models. This feature can also reconcile several puzzling results found in related research. ${ }^{10}$ The carry trade (bond market reallocation in our model) only can explain variability in certain currencies in certain periods because stock reallocation dominates in other cases. High leverage is not always followed by appreciation of the USD because what fund managers have to dump when leverage unwinds are the assets of the HRC, which can be the USD as well.

This research also has important implications for the macro exchange rate literature. Our model suggests that fundamentals must influence the exchange rate through the financial mar-

\footnotetext{
${ }^{7}$ All versus the U.S. dollar. The percentage number is the average of the adjusted R-squared of all periods we tested.

${ }^{8}$ The direct connection between order flow and exchange rate dynamics, which our model is built on, bypasses market clearing conditions, which makes our model a flow, rather than stock, equilibrium model.

${ }^{9}$ We are not saying that the exchange rate is unrelated to macro fundamentals. Rather, we want to emphasize that the fundamentals must affect the exchange rate through market participants trading behavior in the FX market.

${ }^{10}$ See section 4 for more details
} 
kets, which provides a microfoundation for expectation-based macro models. Meanwhile, financial variables that drive exchange rate dynamics are certainly related to fundamentals, but not in a one-to-one mechanical relationship. Information heterogeneity, human psychology, irrational behavior and institutional arrangements can all cause a disconnect between fundamentals and financial variables, especially in the short term. This explains the poor performance of macrobased models in the short run and also contributes to the well-known disconnect puzzle. Risk appetite and expected risks are found by this paper to be significantly connected with exchange rate dynamics in some periods. Hence, our paper suggests as reasonable the conjecture by Engel and West (2010) that the "unobservable fundamental components" probably contain a risk or liquidity premium.

Our paper is in the same spirit as international portfolio rebalance studies. Pavlova and Roberto (2007) suggest that exchange rate movements should be influenced by the same set of factors that govern stock market returns. Hau and Rey $(2004,2006)$ as well as Dunne, Hau, and Moore (2010) further suggest that equity prices and exchange rates are jointly determined through fund managers' portfolio rebalances. In addition to the equity market, this paper also analyzes the impact of portfolio rebalance in the bond market on exchange rate dynamics. The explicit regime switch in the rebalance behavior proposed by our model is greatly underaddressed in the other studies.

Our model also resembles traditional portfolio balance models. These models recognize that dollar assets are limited for certain periods, resulting in international capital flow changing the supply and demand of dollar assets and affecting the exchange rate. Agents in these models are usually assumed to be subject to wealth constraints - the total position of assets cannot exceed wealth. These setups, however, are inconsistent with the reality of the FX market, in which highly leveraged speculators use margin accounts and do not require physical delivery of assets. Thus, either demand or supply of the dollar can be enlarged greatly by leverage and neither is restricted by the quantity of physical assets. Our model accommodates this reality, which becomes the most critical distinction, among others, with respect to the portfolio balance models.

The rest of the paper is arranged as follows. Section 2 constructs a theoretical framework and discusses its implications. Section 3 presents extensive empirical evidence. Section 4 discusses connections to related literature and implications to existing major problems in the field. Section 5 concludes. 


\section{Theoretical Framework}

As previously noted, financial customer order flow is the primary factor driving exchange rate dynamics. FX transactions become necessary when profit-seeking financial customers reallocate portfolios between domestic and foreign assets to maintain a dynamic optimal position. To model this process theoretically, we first determine the optimal portfolio composition for domestic and foreign financial customers, then show how FX order flows are generated by the change of this composition, and finally connect exchange rate dynamics with portfolio reallocation behavior through FX order flows.

\section{1. $\quad$ Model setup}

Suppose home and foreign country each has two funds, one bond fund and one stock fund. Bond funds only contain domestic and foreign money market instruments; ${ }^{11}$ while stock funds contain domestic and foreign stocks as well as domestic money instruments. We assume all the funds share the same size and risk appetite. Also assume no automatic reinvestment of returns. The funds have the following balance sheets:

\begin{tabular}{|c|c|c|c|c|}
\hline & \multicolumn{2}{|c|}{ Home country } & \multicolumn{2}{c|}{ Foreign country } \\
\hline & Assets & Liabilities & Assets & Liabilities \\
\hline Bond fund & $B_{H}^{1}, B_{H}^{*}$ & $V_{H}^{1}$ & $B_{F}^{*, 1}, B_{F}$ & $V_{F}^{1}$ \\
\hline Stock fund & $B_{H}^{2}, S_{H}, S_{H}^{*}$ & $V_{H}^{2}$ & $B_{F}^{*, 2}, S_{F}, S_{F}^{*}$ & $V_{F}^{2}$ \\
\hline
\end{tabular}

where $V$ is equity; $S^{*}$ and $S$ are foreign and domestic stocks; $B^{*}$ and $B$ are foreign and domestic bonds. The subscript $H$ denotes assets held by home country fund while the subscript $F$ denotes foreign country. Note that both $B^{*}$ and $B$ can be negative - either domestic or foreign bonds can be shorted to finance other investments. Further note that all items in the balance sheet are denominated in each country's local currency.

Let $q_{t}^{B, i}, q_{t}^{B^{*}, i}$ be the quantity of domestic and foreign bonds held in the funds where $i=\{1,2\}$. Also let $q_{t}^{S}, q_{t}^{S^{*}}$ be the quantity of domestic and foreign stocks. Again, the subscripts $H$ and $F$ refer to home and foreign funds respectively. Denote the price of domestic and foreign bonds by $p_{t}^{B}$ and $p_{t}^{B^{*}}$ and the price of domestic and foreign stocks by $p_{t}^{S}$ and $p_{t}^{S^{*}}$. Also let $e_{t}$

\footnotetext{
${ }^{11}$ Since FX speculations normally are conducted at short horizons, these bonds are actually money market instruments. For simplicity, we just use bonds in the rest of the paper.
} 
be the spot exchange rate quoted as the dollar price of foreign currency. Thus, each asset held by home and foreign funds in their local currencies are:

$$
\begin{array}{rlrl}
B_{H, t}^{i} & =q_{H, t}^{B, i} \cdot p_{t}^{B} & B_{F, t}^{*, i}=q_{F, t}^{B^{*}, i} \cdot p_{t}^{B^{*}} \\
B_{H, t}^{*}=q_{H, t}^{B^{*}} \cdot p_{t}^{B^{*}} \cdot e_{t} & B_{F, t}=\left(q_{F, t}^{B} \cdot p_{t}^{B}\right) / e_{t} \\
S_{H, t}=q_{H, t}^{S} \cdot p_{t}^{S} & S_{F, t}^{*}=q_{F, t}^{S^{*}} \cdot p_{t}^{S^{*}} \\
S_{H, t}^{*}=q_{H, t}^{S^{*}} \cdot p_{t}^{S^{*}} \cdot e_{t} & S_{F, t}=\left(q_{F, t}^{S} \cdot p_{t}^{S}\right) / e_{t}
\end{array}
$$

We assume domestic and foreign bonds are risk-free in their local currencies, and the dynamics of their prices can be expressed as:

$$
\begin{aligned}
\frac{d p_{t}^{B}}{p_{t}^{B}} & =i_{t} d t \\
\frac{d p_{t}^{B^{*}}}{p_{t}^{B^{*}}} & =i_{t}^{*} d t
\end{aligned}
$$

where $i_{t}$ and $i_{t}^{*}$ are domestic and foreign nominal interest rates. Short term interest rates are strongly affected by monetary policies, which we assume exogenous in our model.

Domestic and foreign stocks are risky assets and their prices are assumed to follow the following dynamics in their local currencies:

$$
\begin{aligned}
& \frac{d p_{t}^{S}}{p_{t}^{S}}=\bar{r}_{t} d t+\sigma_{S, t} d w_{t}^{S} \\
& \frac{d p_{t}^{S^{*}}}{p_{t}^{S^{*}}}=\bar{r}_{t}^{*} d t+\sigma_{S^{*}, t} d w_{t}^{S^{*}}
\end{aligned}
$$

where $\bar{r}_{t}^{*}$ and $\bar{r}_{t}$ are the expected returns of foreign and domestic stocks, and $\sigma_{S, t}$ and $\sigma_{S^{*}, t}$ are the standard deviations of the returns. Note that $\bar{r}_{t}^{*}, \bar{r}_{t}, \sigma_{S, t}$ and $\sigma_{S^{*}, t}$ are time-varying as market conditions change. The variables $w_{t}^{S}$ and $w_{t}^{S^{*}}$ represent standard Brownian motions that drive domestic and foreign stock prices respectively.

Since unconditional dynamics of the spot exchange rate basically follow a random walk, we assume its return is just white noise: ${ }^{12}$

$$
\frac{d e_{t}}{e_{t}}=\sigma_{e, t} d w_{t}^{e}
$$

\footnotetext{
${ }^{12}$ Assuming a zero conditional mean of exchange rate change is contradictory with the ultimate goal of the model - to determine what drives exchange rate change. Before we relax this assumption in section 2.4., we use it to simplify analysis and facilitate derivation of an explicit solution to the model.
} 
where $\sigma_{e, t}$ is time-varying exchange rate volatility and $w_{t}^{e}$ is the Brownian motion that drives exchange rate change.

\subsection{Domestic funds portfolio reallocation}

\subsubsection{Optimal portfolio composition}

Equity of domestic bond fund, by nature of balance sheet, is:

$$
V_{H, t}^{1}=B_{H, t}^{1}+B_{H, t}^{*}
$$

Let $w_{H, t}^{B^{*}}$ denotes the weight of foreign bond, the only risky asset for this fund, the expected return of the portfolio and its variance become:

$$
\begin{aligned}
E_{t}\left(\frac{d V_{H, t}^{1}}{V_{H, t}^{1}}\right) & =\left[\left(1-w_{H, t}^{B^{*}}\right) i_{t}+w_{H, t}^{B^{*}} i_{t}^{*}\right] d t \\
\operatorname{Var}_{t}\left(\frac{d V_{H, t}^{1}}{V_{H, t}^{1}}\right) & =\left(w_{H, t}^{B^{*}}\right)^{2} \sigma_{e, t}^{2} d t
\end{aligned}
$$

To keep the model as simple as possible while retaining the key ingredients needed to highlight the role of portfolio reallocation in affecting exchange rate, we just use the simplest meanvariance optimization framework to solve for optimal assets allocation. Given the degree of risk aversion $\gamma_{H, t}$ (i.e. risk appetite), the optimization problem can be written as:

$$
\underset{w_{H, t}^{B^{*}}}{\operatorname{aax}_{w_{H, t}}}\left[\left(1-w_{t}^{B^{*}}\right) i_{t}+w_{H, t_{t}^{B^{*}}}^{B^{*}}\right]-\frac{1}{2} \gamma_{H, t}\left(w_{H, t}^{B^{*}}\right)^{2} \sigma_{e, t}^{2}
$$

The optimal holding of foreign bond can be easily solved as:

$$
B_{H, t}^{*}=\frac{V_{H, t}^{1}}{\gamma_{H, t}} \cdot \frac{i_{t}^{*}-i_{t}}{\sigma_{e, t}^{2}}
$$

Similarly, domestic stock fund's equity is:

$$
V_{H, t}^{2}=B_{H, t}^{2}+S_{H, t}+S_{H, t}^{*}
$$


where both domestic and foreign stocks are risky assets in this fund. Define vector $W_{H, t}, P_{t}$ as:

$$
W_{H, t}=\left[\begin{array}{c}
w_{H, t}^{S} \\
w_{H, t}^{S^{*}}
\end{array}\right]=\left[\begin{array}{c}
S_{H, t} / V_{H, t}^{2} \\
S_{H, t}^{*} / V_{H, t}^{2}
\end{array}\right], P_{t}=\left[\begin{array}{c}
p_{t}^{S} \\
p_{t}^{S^{*}} \cdot e_{t}
\end{array}\right]
$$

According to equations (5) through (9), the expected return of the risky assets in the portfolio is:

$$
R_{t}=E_{t}\left(\frac{d P_{t}}{P_{t}}\right)=\left[\begin{array}{c}
\bar{r}_{t} \\
\bar{r}_{t}^{*}+\sigma_{S^{*}, e}
\end{array}\right] d t
$$

Thus expected return of the portfolio can be written in matrix format as:

$$
E_{t}\left(\frac{d V_{H, t}^{2}}{V_{H, t}^{2}}\right)=\left[\left(1-I^{\prime} W_{H, t}\right) i_{t}+R_{t}^{\prime} W_{H, t}\right] d t
$$

where $I$ is a $2 \times 1$ unit vector.

The conditional variance of the portfolio's return is also given by equations (5) through (9) as:

$$
\begin{aligned}
\operatorname{Var}_{t}\left(\frac{d V_{H, t}^{2}}{V_{H, t}^{2}}\right) & =\operatorname{Var}\left(W_{H, t}^{\prime} \cdot \frac{d P_{t}}{P_{t}}\right)=\left(W_{H, t}^{\prime} \cdot \Phi_{t} \cdot W_{H, t}\right) d t \\
\text { where } \Phi_{t} & =\operatorname{Var}\left(\frac{d P_{t}}{P_{t}}\right)=\left[\begin{array}{cc}
\sigma_{S}^{2} & \sigma_{S, S^{*}}+\sigma_{S, e} \\
\sigma_{S^{*}, S}+\sigma_{e, S} & \sigma_{S^{*}}^{2}+\sigma_{e}^{2}+2 \sigma_{e, S^{*}}
\end{array}\right]_{t}
\end{aligned}
$$

Again, standard optimization problem:

$$
\underset{W_{H, t}}{\operatorname{Max}}\left[\left(1-I^{\prime} W_{H, t}\right) i_{t}+R_{t}^{\prime} W_{H, t}\right]-\frac{1}{2} \gamma_{H, t}\left(W_{H, t}^{\prime} \cdot \Phi_{t} \cdot W_{H, t}\right)
$$

And standard solution for the optimal holding of the risky assets:

$$
\left[\begin{array}{c}
S_{H, t} \\
S_{H, t}^{*}
\end{array}\right]=V_{H, t}^{2} \frac{\left(R_{t}-i_{t} I\right)}{\gamma_{H, t}} \cdot \Phi_{t}^{-1}
$$

To simplify the analysis further, we assume different assets' returns are independent. ${ }^{13}$ Thus

\footnotetext{
${ }^{13}$ This assumption is made to strive for analytical solution and more intuitive analysis later in the paper. This assumption is certainly unrealistic, but numerical simulation without this assumption, using the data described in section 3.1., obtains the consistent conclusions suggested by the simplified model.
} 
the solution above can be simplified as:

$$
\left[\begin{array}{c}
S_{H, t} \\
S_{H, t}^{*}
\end{array}\right]=\frac{V_{H, t}^{2}}{\gamma_{H, t}} \cdot\left[\begin{array}{c}
\frac{\bar{r}_{t}-i_{t}}{\sigma_{S, t}^{2}} \\
\frac{\bar{r}_{t}^{*}-i_{t}}{\sigma_{S^{*}, t}^{2}+\sigma_{e, t}^{2}}
\end{array}\right]
$$

Since the reallocation between $B_{H}^{2}$ and $S_{H}$ does not involve FX transactions, we focus only on the reallocation between $B_{H}^{1}$ and $B_{H}^{*}$ (bond reallocation) as well as $B_{H}^{2}$ and $S_{H}^{*}$ (stock reallocation) to show the generation process of $\mathrm{FX}$ order flow.

\subsubsection{Bond reallocation}

Equation (10) gives the optimal holding of $B_{H, t}^{*}$ as:

$$
B_{H, t}^{*}=\frac{V_{H, t}^{1}}{\gamma_{H, t}} \cdot \frac{i_{t}^{*}-i_{t}}{\sigma_{e, t}^{2}}
$$

This equation suggests a positive optimal holding of foreign bond if the foreign interest rate is higher than the domestic rate $\left(i_{t}^{*}>i_{t}\right)$. Leveraged institutions (such as hedge funds) can even short domestic bond to hold more foreign bond than their equity. Unleveraged institutions (such as mutual funds), however, are strictly prohibited by the SEC from doing so, and, consequently, their maximum holding of foreign bond is their equity capital. In the opposite case (i.e. $\left.i_{t}^{*}<i_{t}\right)$, equation (12) suggests a negative optimal holding of foreign bond, which means that fund managers should short foreign bond to invest in domestic bond. Once again, this is feasible for leveraged institutions but not allowed for unleveraged institutions, who would just maintain zero foreign bond in this case. ${ }^{14}$ Thus equation (12) gives the optimal holding of foreign bond for leveraged institutions, while for unleveraged institutions, it should be more accurately written as:

$$
B_{H, t}^{*}= \begin{cases}\frac{V_{H, t}^{1}}{\gamma_{H, t}} \cdot \frac{i_{t}^{*}-i_{t}}{\sigma_{e, t}^{2}}, \forall B_{H, t}^{*} \leqslant V_{H, t}^{1} & \text { if } i_{t}^{*}-i_{t}>0 \\ 0 & \text { otherwise }\end{cases}
$$

Given $i_{t}^{*}>i_{t}$, according to equations (12) and (13), increasing the interest rate differential suggests a higher optimal position of foreign bond. To attain the new optimal position, fund managers need to buy more foreign bond (and sell domestic bond). Such a portfolio reallocation causes positive order flow for foreign currency. By the same logic, decreasing exchange rate risk

\footnotetext{
${ }^{14}$ Unleveraged institutions has the constraint of $0 \leqslant w_{H, t}^{B^{*}} \leqslant 1$ in their optimization problem. So when $i_{t}^{*}<i_{t}$, foreign bond is inferior to domestic bond in the mean-variance framework, and we have corner solution of $w_{H, t}^{B^{*}}=0$.
} 
$\sigma_{e, t}^{2}$, increasing risk appetite (i.e. decreasing $\gamma_{H, t}$ ) and increasing equity $V_{H, t}^{1}$ (i.e. investors inject additional money into the fund) all lead to positive order flow for the foreign currency.

If the foreign interest rate is lower than the domestic rate (i.e. $i_{t}^{*}<i_{t}$ ), fund managers in leveraged institutions should short foreign bond to invest in domestic bond. In this case, increasing the magnitude of the interest rate differential, decreasing exchange rate risk, increasing equity and increasing risk appetite all lead to shorting more foreign bond (i.e. long more domestic bond), which generates negative order flow for foreign currency (i.e. positive order flow for the domestic currency). In contrast, unleveraged domestic institutions just maintain zero foreign bond in this case, hence the changing market conditions would not generate any FX order flow from them. In this case, although leveraged and unleveraged institutions behave differently, they do not conflict in terms of the direction of order flow.

If we denote $O F$ as order flow for foreign currency (i.e. positive $O F$ means net buy order of foreign currency, the same definition throughout the paper), the implications discussed above can be summarized in the table below:

\begin{tabular}{|l|l|l|l|l|l|l|}
\hline & types of funds & $B_{H, t}^{*}$ & $\left|i_{t}^{*}-i_{t}\right| \uparrow$ & $\sigma_{e, t}^{2} \uparrow$ & $V_{H, t}^{1} \uparrow$ & $\gamma_{H, t} \uparrow$ \\
\hline \multirow{4}{*}{$i_{t}^{*}>i_{t}$} & mutual funds & $B_{H, t}^{*}>0$ & $O F>0$ & $O F<0$ & $O F>0$ & $O F<0$ \\
& hedge funds & $B_{H, t}^{*}>0$ & $O F>0$ & $O F<0$ & $O F>0$ & $O F<0$ \\
& net effect & $B_{H, t}^{*}>0$ & $O F>0$ & $O F<0$ & $O F>0$ & $O F<0$ \\
\hline \multirow{2}{*}{$i_{t}^{*}<i_{t}$} & mutual funds & $B_{H, t}^{*}=0$ & $O F=0$ & $O F=0$ & $O F=0$ & $O F=0$ \\
& hedge funds & $B_{H, t}^{*}<0$ & $O F<0$ & $O F>0$ & $O F<0$ & $O F>0$ \\
& net effect & $B_{H, t}^{*}<0$ & $O F<0$ & $O F>0$ & $O F<0$ & $O F>0$ \\
\hline
\end{tabular}

Thus, in the scenario of $i_{t}^{*}>i_{t}$, the dynamics of optimal foreign bond held by the domestic bond fund is given by equation (12) as:

$$
\Delta B_{H, t}^{*}=\Delta\left(i_{t}^{*}-i_{t}\right)+\Delta V_{H, t}^{1}-\Delta \gamma_{H, t}-\Delta \sigma_{e, t}^{2}
$$

where $\Delta$ represents percentage change (the same definition throughout the paper unless noted). In the scenario of $i_{t}^{*}<i_{t}$, the dynamics of optimal foreign bond are:

$$
\Delta B_{H, t}^{*}=-\left[\Delta\left(i_{t}-i_{t}^{*}\right)+\Delta V_{H, t}^{1}-\Delta \gamma_{H, t}-\Delta \sigma_{e, t}^{2}\right]
$$


Define an indicator $I_{i_{t}^{*}>i_{t}}$ as

$$
I_{i_{t}^{*}>i_{t}}= \begin{cases}1 & \text { if } i_{t}^{*}>i_{t} \\ -1 & \text { if } i_{t}^{*}<i_{t}\end{cases}
$$

A universal expression of $\Delta B_{H, t}^{*}$ therefore becomes

$$
\Delta B_{H, t}^{*}=\Delta\left(i_{t}^{*}-i_{t}\right)+I_{i_{t}^{*}>i_{t}}\left(\Delta V_{H, t}^{1}-\Delta \gamma_{H, t}-\Delta \sigma_{e, t}^{2}\right)
$$

For any currency pair, the currency with higher interest rate can be called the high-returncurrency (HRC) in the money market (i.e. short-term bond market). Equation (12) and the table above show that the optimal bond allocation is always to short the low-return-currency and long the high-return-currency. This strategy is often referred to as the "Carry Trade". Our model (equations (14) and (15) ) also suggests that the carry trade does not automatically cause the currency with the higher interest rate to appreciate. Instead, whether or not the HRC appreciates is affected by changes in market conditions that include the magnitude of interest rate differential, expected exchange rate risk, the equity of the funds, and risk appetite of market participants. Our model further shows that any favorable (adverse) change of these factors always causes positive (negative) order flow for the HRC. Therefore, HRC status determines the direction of order flow each of these factors would cause.

\subsubsection{Stock reallocation}

Equation (11) gives the optimal holding of foreign stocks $S_{H, t}^{*}$ as:

$$
S_{H, t}^{*}=\frac{V_{H, t}^{2}}{\gamma_{H, t}} \cdot \frac{\bar{r}_{t}^{*}-i_{t}}{\sigma_{S^{*}, t}^{2}+\sigma_{e, t}^{2}}
$$

This optimal allocation is solved without any constraints previously, while corner solutions arise in some scenarios due to the existence of certain constraints in reality. In particular, the data, introduced in section 3.1., show that, given a pair of countries, even for the country which had lower stock risk originally, its stock risk combined with the exchange rate risk is almost always higher than the other country's stock risk alone (i.e. $\left.\sigma_{S^{*}, t}^{2}+\sigma_{e, t}^{2}>\sigma_{S, t}^{2}\right){ }^{15}$ Thus, if foreign stocks cannot generate higher expected return than domestic ones (i.e. $\bar{r}_{t}^{*}<\bar{r}_{t}$ ), in

\footnotetext{
${ }^{15}$ This claim can be supported by estimation of domestic and foreign stock return risk as well as exchange rate risk at the monthly horizon with corresponding GARCH specification and data described in section 3.1.. The results, not included in the paper due to length limitations, are available upon request.
} 
the optimization framework we specified in sections 2.1. and 2.2., foreign stocks are inferior to domestic stocks, and the home country stock fund should not hold any foreign stocks (i.e. corner solution $\left.w_{H, t}^{S^{*}}=0\right)$.

Stock return is usually expected to be higher than money market return. The opposite scenario (i.e. $\bar{r}_{t}^{*}<i_{t}$ ) is also possible (usually during economic recessions and financial crises), in which case equation (16) suggests a negative holding of foreign stocks (i.e. short foreign stocks to invest in domestic bonds). This is prohibited for unleveraged institutions and practically infeasible for leveraged institutions. The short sale of stocks is banned in some countries, and heavily regulated, especially during market downturns due to fears of over-volatility, in those countries where permitted. ${ }^{16}$ Hence, given $\bar{r}_{t}^{*}<i_{t}$, it is rational to reallocate all foreign stocks into money market assets (i.e. also a corner solution $w_{H, t}^{S^{*}}=0$ ).

Thus, a more accurate expression of $S_{H, t}^{*}$ for both leveraged and unleveraged funds should be:

$$
S_{H, t}^{*}= \begin{cases}\frac{V_{H, t}^{2}}{\gamma_{H, t}} \cdot \frac{\bar{r}_{t}^{*}-i_{t}}{\sigma_{S^{*}, t}^{2}+\sigma_{e, t}^{2}} & \text { if } \bar{r}_{t}^{*}>\bar{r}_{t} \text { and } \bar{r}_{t}^{*}>i_{t} \\ 0 & \text { otherwise }\end{cases}
$$

Given $\bar{r}_{t}^{*}>\bar{r}_{t}$ (i.e. foreign currency is the HRC in the stock market) and $\bar{r}_{t}^{*}>i_{t}$ (i.e. market boom periods), fund managers need to buy more foreign stocks to obtain the new optimal position suggested by equation (17) when cross risk premium $\left(\bar{r}_{t}^{*}-i_{t}\right)$ increases, which causes positive order flow for the foreign currency. By the same logic, a lower exchange rate risk, lower stock risk, higher equity capital, and higher risk appetite all lead to positive order flow for the foreign currency. Thus, in this scenario, the dynamics of optimal foreign stocks held by the home country stock fund is given by equation (17) in a simplified linear format as:

$$
\Delta S_{H, t}^{*}=\Delta\left(\bar{r}_{t}^{*}-i_{t}\right)+\Delta V_{H, t}^{2}-\Delta \gamma_{H, t}-\Delta \sigma_{S^{*}, t}^{2}-\Delta \sigma_{e, t}^{2}
$$

When the market experiences a downturn (i.e. $\bar{r}_{t}^{*}<i_{t}$ ), equation $(17)$ suggests zero position of foreign stocks. If the portfolio contains foreign stocks before the downturn (which must imply $\bar{r}_{-t}^{*}>\bar{r}_{-t}$ ), then fund managers should immediately dump all foreign stocks as the downturn starts. In reality, however, this process is not instantaneous for several reasons. As stock market returns are uncertain, occasional negative returns do not ensure an imminent major downturn. Moreover, mutual funds usually have restrictions on frequent reallocations. ${ }^{17}$ Even

\footnotetext{
${ }^{16}$ For example, the SEC banned short sale during 2008 financial crisis in the U.S..

${ }^{17}$ For example, Vanguard does not allow investors to enter the same funds again less than two months after
} 
for the financial institutions without such restrictions, selling all stocks immediately after the market starts declining is not necessarily a rational decision, either because the market plunge might be temporary or because selling upon market panic is liable to lose even more money. Hence, we assume that the foreign stocks will be unloaded at a slower speed, which, intuitively, should depend upon the severity of the downturn (measured by change of stock market risk premium $\left(\bar{r}_{t}^{*}-i_{t}\right)$ ), fund managers' risk appetite, clients' intention to withdraw equity, and a market panic index (measured by expected market volatility). Thus, in the scenario of $\bar{r}_{t}^{*}<i_{t}$ and $\bar{r}_{-t}^{*}>\bar{r}_{-t}$, equation (18) still describes the dynamics of optimal foreign stocks.

If the fund does not hold any foreign stocks before the downturn (i.e. $\left(\bar{r}_{-t}^{*}<\bar{r}_{-t}\right) \&$ $\left.\left(\bar{r}_{t}^{*}<i_{t}\right)\right)$, fund managers have no foreign stocks to dump during the downturn. Also, if foreign stocks do not offer higher return during market booms (i.e. $\left(\bar{r}_{t}^{*}<\bar{r}_{t}\right) \&\left(\bar{r}_{t}^{*}>i_{t}\right)$ ), fund managers would not hold any foreign stocks. In both cases, the dynamics of optimal foreign stocks held by the domestic fund, as suggested by equation (17), is $\Delta S_{H, t}^{*}=0$. These implications can be summarized in the table below:

\begin{tabular}{|l|l|l|l|l|l|}
\hline Scenarios & $S_{H, t}^{*}$ & $\left|\bar{r}_{t}^{*}-i_{t}\right| \uparrow$ & $\sigma_{e, t}^{2}, \sigma_{S^{*}, t}^{2} \uparrow$ & $V_{H, t}^{2} \uparrow$ & $\gamma_{H, t} \uparrow$ \\
\hline$\left(\bar{r}_{t}^{*}>\bar{r}_{t}\right) \&\left(\bar{r}_{t}^{*}>i_{t}\right)$ & $S_{H, t}^{*}>0$ & $O F>0$ & $O F<0$ & $O F>0$ & $O F<0$ \\
\hline$\left(\bar{r}_{-t}^{*}>\bar{r}_{-t}\right) \&\left(\bar{r}_{t}^{*}<i_{t}\right)^{18}$ & $S_{H, t}^{*}=0$ & $O F<0^{19}$ & $O F<0$ & $O F>0^{20}$ & $O F<0$ \\
\hline$\left(\bar{r}_{t}^{*}<\bar{r}_{t}\right) \&\left(\bar{r}_{t}^{*}>i_{t}\right)$ & $S_{H, t}^{*}=0$ & $O F=0$ & $O F=0$ & $O F=0$ & $O F=0$ \\
\hline$\left(\bar{r}_{-t}^{*}<\bar{r}_{-t}\right) \&\left(\bar{r}_{t}^{*}<i_{t}\right)$ & $S_{H, t}^{*}=0$ & $O F=0$ & $O F=0$ & $O F=0$ & $O F=0$ \\
\hline
\end{tabular}

\subsection{Foreign funds portfolio reallocation}

We do the same analysis for foreign funds. The theoretical framework for domestic funds is perfectly symmetric and can be directly applied to foreign funds. Accordingly, the optimal holding of risky assets for foreign bond and stock funds can be solved as:

\footnotetext{
the funds have been sold.

${ }^{18} \bar{r}_{t}^{*}<i_{t}$ means the stock market experiences a downturn. $\bar{r}_{-t}^{*}>\bar{r}_{-t}$ means foreign stocks have higher returns than domestic stocks before the downturn.

${ }^{19}$ During downturns, $\bar{r}_{t}^{*}-i_{t}<0$, so $\left|\bar{r}_{t}^{*}-i_{t}\right| \uparrow$ means $\bar{r}_{t}^{*}-i_{t}$ is decreasing, causing the order flow to be further negative.

${ }^{20}$ Here by indicating that increasing equity causes positive order flow, we mean the equity change and order flow have the same sign. During financial downturns, investors usually withdraw the money so that the equity change should be negative and the order flow should be negative too.
} 


$$
\begin{aligned}
B_{F, t} & =\frac{V_{F, t}^{1}}{\gamma_{F, t}} \cdot \frac{i_{t}-i_{t}^{*}}{\sigma_{e, t}^{2}} \\
{\left[\begin{array}{c}
S_{F, t}^{*} \\
S_{F, t}
\end{array}\right] } & =\frac{V_{F, t}^{2}}{\gamma_{F, t}} \cdot\left[\begin{array}{c}
\frac{\bar{r}_{t}^{*}-i_{t}^{*}}{\sigma_{S}^{2}} \\
\frac{\bar{s}_{t}-i_{t}^{*}}{\sigma_{S, t}^{2}+\sigma_{e, t}^{2}}
\end{array}\right]
\end{aligned}
$$

Since the reallocation between $B_{F}^{*}$ and $S_{F}^{*}$ does not involve FX transactions, the reallocation between $B_{F}^{*}$ and $B_{F}$ as well as $B_{F}^{*}$ and $S_{F}$ become our focus for the foreign funds. Following the similar analysis for the domestic funds, the dynamics of domestic bond held by the foreign bond fund is given by (19) as:

$$
\Delta B_{F, t}=\Delta\left(i_{t}-i_{t}^{*}\right)+\left(-I_{i_{t}^{*}>i_{t}}\right)\left(\Delta V_{F, t}^{1}-\Delta \gamma_{F, t}-\Delta \sigma_{e, t}^{2}\right)
$$

Given $\left(\bar{r}_{t}^{*}<\bar{r}_{t} \& \bar{r}_{t}>i_{t}^{*}\right)$ or $\left(\bar{r}_{t}<i_{t}^{*} \& \bar{r}_{-t}^{*}<\bar{r}_{-t}\right)$, the dynamics of domestic stocks held by the foreign stock fund is given by equation (20) as:

$$
\Delta S_{F, t}=\Delta\left(\bar{r}_{t}-i_{t}^{*}\right)+\Delta V_{F, t}^{2}-\Delta \gamma_{F, t}-\Delta \sigma_{S, t}^{2}-\Delta \sigma_{e, t}^{2}
$$

In other scenarios (i.e. $\left(\bar{r}_{-t}^{*}>\bar{r}_{-t}\right) \&\left(\bar{r}_{t}<i_{t}^{*}\right)$ or $\left.\left(\bar{r}_{t}^{*}>\bar{r}_{t}\right) \&\left(\bar{r}_{t}>i_{t}^{*}\right)\right), \Delta S_{F, t}=0$.

For any currency pair, the currency with higher expected stock return can be called the high-return-currency in the stock market. Equations (18) and (21) show that optimal stock allocation strategy is always to long HRC stocks during market booms and dump previously accumulated HRC stocks during market downturns. Any favorable (adverse) change of the order flow determinants always cause positive (negative) order flow for the HRC, and therefore stock market HRC status determines the direction of order flow each of these factors would cause.

Consistence of order flows generated by domestic and foreign funds can be summarized in the table below, from which we can see that domestic and foreign reallocations never result in 
conflicting order flows.

\begin{tabular}{|l|l|l|l|}
\hline & Scenarios & Domestic Funds & Foreign Funds \\
\hline \multirow{5}{*}{ bond reallocation } & $\left(i_{t}^{*} \gtrless i_{t}\right)$ & $O F\left(=\Delta B_{H, t}^{*}\right) \gtrless 0$ & $O F\left(=-\Delta B_{F, t}\right) \gtrless 0$ \\
\hline \multirow{5}{*}{ stock reallocation } & $\left(\bar{r}_{t}^{*}>\bar{r}_{t}\right) \&\left(\bar{r}_{t}^{*}>i_{t}\right)$ & $O F\left(=\Delta S_{H, t}^{*}\right)>0$ & $O F=0\left(S_{F, t}=0\right)$ \\
\cline { 2 - 4 } & $\left(\bar{r}_{t}^{*}<\bar{r}_{t}\right) \&\left(\bar{r}_{t}>i_{t}^{*}\right)$ & $O F=0\left(S_{H, t}^{*}=0\right)$ & $O F\left(=-\Delta S_{F, t}\right)<0$ \\
\cline { 2 - 4 } & $\left(\bar{r}_{-t}^{*}>\bar{r}_{-t}\right) \&\left(\bar{r}_{t}^{*}<i_{t}\right)$ & $O F\left(=\Delta S_{H, t}^{*}\right)<0$ & $O F=0\left(S_{F,-t / t}=0\right)$ \\
\cline { 2 - 4 } & $\left(\bar{r}_{-t}^{*}<\bar{r}_{-t}\right) \&\left(\bar{r}_{t}<i_{t}^{*}\right)$ & $O F=0\left(S_{H,-t / t}^{*}=0\right)$ & $O F\left(=-\Delta S_{F, t}\right)>0$ \\
\hline
\end{tabular}

\subsection{Portfolio reallocation with conditional mean in spot rate change}

In the model above, we assume an exchange rate with no expected direction (see equation (9)). In reality, institutional investors know their intended FX transactions, based upon which they can expect an impact on the spot rate change, which implies a certain direction for the exchange rate movement. With the conditional mean, the carry trade or foreign stock investment not only generate profit from interest rate differential or stock return, but also from exchange rate change. So the non-zero conditional mean is essentially an additional expected return and should be mapped completely into the change of optimal asset positions. Hence portfolio reallocation (percentage change) with conditional mean (denoted as $\Delta B_{H, t}^{*^{\prime}}, \Delta S_{H, t}^{*^{\prime}}, \Delta B_{F, t}^{\prime}, \Delta S_{F, t}^{\prime}$, as opposed to the variables without "'" derived with zero mean previously) becomes:

$$
\begin{aligned}
\Delta B_{H, t}^{*^{\prime}}=\Delta B_{H, t}^{*}+E_{H, t}^{1}\left(\Delta e_{t}\right) ; & \Delta B_{F, t}^{\prime}=\Delta B_{F, t}-E_{F, t}^{1}\left(\Delta e_{t}\right) \\
\Delta S_{H, t}^{*^{\prime}}=\Delta S_{H, t}^{*}+E_{H, t}^{2}\left(\Delta e_{t}\right) ; & \Delta S_{F, t}^{\prime}=\Delta S_{F, t}-E_{F, t}^{2}\left(\Delta e_{t}\right)
\end{aligned}
$$

where $E_{H, t}^{i}\left(\Delta e_{t}\right)$ and $E_{F, t}^{i}\left(\Delta e_{t}\right)$ are each fund's expected future exchange rate change.

A fund manager certainly knows her own intended FX orders will have an impact on the future spot rate, and the impact should be larger if she is better informed. If we use $\lambda_{t}$ $\left(0<\lambda_{t}<1\right)$ to denote such an information advantage parameter, ${ }^{21}$ the expected exchange rate

\footnotetext{
${ }^{21}$ To simplify the expression of model solutions, we assume the parameter is the same for domestic and foreign funds.
} 
change in each fund can be written as: ${ }^{22}$

$$
\begin{aligned}
& E_{H, t}^{1}\left(\Delta e_{t}\right)=\lambda_{t} \Delta B_{H, t}^{*^{\prime}} ; \quad E_{H, t}^{2}\left(\Delta e_{t}\right)=\lambda_{t} \Delta S_{H, t}^{*^{\prime}} \\
& E_{F, t}^{1}\left(\Delta e_{t}\right)=\lambda_{t} \Delta B_{F, t}^{\prime} ; \quad E_{F, t}^{2}\left(\Delta e_{t}\right)=\lambda_{t} \Delta S_{F, t}^{\prime}
\end{aligned}
$$

Equation system (22) through (25) gives the solution of the portfolio reallocation with nonzero conditional mean as:

$$
\begin{aligned}
\Delta B_{H, t}^{*^{\prime}} & =\frac{1}{1-\lambda_{t}} \Delta B_{H, t}^{*} ; \quad \Delta S_{H, t}^{*^{\prime}}=\frac{1}{1-\lambda_{t}} \Delta S_{H, t}^{*} \\
\Delta B_{F, t}^{\prime} & =\frac{1}{1-\lambda_{t}} \Delta B_{F, t} ; \quad \Delta S_{F, t}^{\prime}=\frac{1}{1-\lambda_{t}} \Delta S_{F, t}
\end{aligned}
$$

The equations above imply that dropping the zero-mean assumption does not change the direction of order flow, but rather amplifies the order flow. When a fund manager is better informed (i.e. $\lambda_{t}$ is bigger), her intended FX order is a better predictor of future exchange rate return. Knowing this, she would submit a larger order. Such a mechanism highlights information heterogeneity among market participants. The story that fund managers expect price increases so start buying, which in turn reifies the expected increase in the price, depicts a self-fulfilling asset pricing process for which Plantin and Shin (2008) has a more rigorous framework.

\subsection{Aggregate order flow and exchange rate dynamics}

With all funds' portfolio reallocations between domestic and foreign assets derived in the previous sections, particularly considering the existence of corner solutions in stock reallocations, aggregate FX order flow (in monetary amount) can be easily obtained as:

$$
O F_{t}=\left|B_{H, t}^{*}\right| \Delta B_{H, t}^{*^{\prime}}+I_{\bar{r}_{t}^{*}>\bar{r}_{t}}\left|S_{H, t}^{*}\right| \Delta S_{H, t}^{*^{\prime}}-\left|B_{F, t}\right| \Delta B_{F, t}^{\prime}-I_{\bar{r}_{t}^{*}<\bar{r}_{t}}\left|S_{F, t}\right| \Delta S_{F, t}^{\prime}
$$

where indicators $I_{i_{t}^{*}>i_{t}}, I_{\bar{r}_{t}^{*}>\bar{r}_{t}}$ represent HRC in the stock market and are defined as below:

$$
I_{\bar{r}_{t}^{*}>\bar{r}_{t}}=\left\{\begin{array}{cc}
1 & \text { if } \bar{r}_{t}^{*}>\bar{r}_{t} \\
0 & \text { if } \bar{r}_{t}^{*}<\bar{r}_{t}
\end{array}, I_{\bar{r}_{t}^{*}<\bar{r}_{t}}= \begin{cases}1 & \text { if } \bar{r}_{t}^{*}<\bar{r}_{t} \\
0 & \text { if } \bar{r}_{t}^{*}>\bar{r}_{t}\end{cases}\right.
$$

\footnotetext{
${ }^{22}$ Since funds are separate in our model, fund managers should have no knowledge of other funds' intended transactions, which are private information in the market.
} 
According to our analysis in section (2.2.3.), note again that during downturn scenarios, ${\overline{r_{t}^{*}}}_{t}>\bar{r}_{t}$ and $I_{\bar{r}_{t}^{*}<\bar{r}_{t}}$ are determined by stock market performance before the downturn. ${ }^{23}$

As suggested by FX market microstructure literature, exchange rate dynamics should be proportional to aggregate order flow. So plugging previously derived $B_{H, t}^{*}, S_{H, t}^{*}, B_{F, t}, S_{F, t}$ and $\Delta B_{H, t}^{*^{\prime}}, \Delta S_{H, t}^{*^{\prime}}, \Delta B_{F, t}^{\prime}, \Delta S_{F, t}^{\prime}$ into the equation above gives the solution of our model on exchange rate dynamics:

$$
\begin{aligned}
\Delta e_{t}= & \frac{V_{t}}{1-\lambda_{t}}\left\{2 W_{B^{*}} \Delta\left(i_{t}^{*}-i_{t}\right)+\right. \\
& {\left[I_{\bar{r}_{t}^{*}>\bar{r}_{t}} W_{S^{*}}\left(\Delta\left(\bar{r}_{t}^{*}-i_{t}\right)-\Delta \sigma_{S^{*}, t}^{2}\right)-I_{\bar{r}_{t}^{*}<\bar{r}_{t}} W_{S}\left(\Delta\left(\bar{r}_{t}-i_{t}^{*}\right)-\Delta \sigma_{S, t}^{2}\right)\right]+} \\
& {\left.\left[2 W_{B^{*}} I_{i_{t}^{*}>i_{t}}+\left(I_{\bar{r}_{t}^{*}>\bar{r}_{t}} W_{S^{*}}-I_{\bar{r}_{t}^{*}<\bar{r}_{t}} W_{S}\right)\right]\left(\Delta V_{t}-\Delta \gamma_{t}-\Delta \sigma_{e, t}^{2}\right)\right\} }
\end{aligned}
$$

where $^{24}$

$$
\begin{aligned}
W_{B^{*}} & =W_{B}=\frac{\left|i_{t}^{*}-i_{t}\right|}{\gamma_{t} \sigma_{e, t}^{2}}, W_{S^{*}}=\frac{\left|\bar{r}_{t}^{*}-i_{t}\right|}{\gamma_{t}\left(\sigma_{S^{*}, t}^{2}+\sigma_{e, t}^{2}\right)}, W_{S}=\frac{\left|\bar{r}_{t}-i_{t}^{*}\right|}{\gamma_{t}\left(\sigma_{S, t}^{2}+\sigma_{e, t}^{2}\right)} \\
V_{t} & =V_{H, t}^{i}=V_{F, t}^{i} ; \quad \gamma_{t}=\gamma_{H, t}=\gamma_{F, t}
\end{aligned}
$$

This solution considers the exchange rate dynamics as a weighted average of several explanatory factors. Weights $W_{B^{*}}, W_{S^{*}}$ and $W_{S}$, representing the relative position of bonds and stocks held in the portfolios, reflect the relative dominance of the reallocation of each asset class. Indicators $I_{i_{t}^{*}>i_{t}}, I_{\bar{r}_{t}^{*}>\bar{r}_{t}}$ and $I_{\bar{r}_{t}^{*}<\bar{r}_{t}}$ indicate HRCs in the bond and stock markets. The first line of the solution represents the FX order flow solely affected by bond reallocation, which is positively driven by the relative return of foreign and domestic bonds. The second line suggests increasing stock risk premium and decreasing stock risk would lead to increased holding of HRC stocks and therefore drive the HRC to appreciate. The third line contains the common factors that affect both bond and stock reallocations - equity, risk appetite and exchange rate risk. A favorable change of these factors should increase holding of the overall HRC, which is determined by relative dominance of the two reallocations (reflected by relationship between $2 W_{B^{*}}$ and $\left.W_{S^{*}}\left(W_{S}\right)\right)$ given conflicting HRCs in the two markets. The relative dominance also becomes critical to determine overall effect if the first and second line give opposite reallocation directions.

\footnotetext{
${ }^{23}$ i.e. $I_{\bar{r}_{t}^{*}>\bar{r}_{t}}=\left\{\begin{array}{ll}1 & \text { if } \bar{r}_{-t}^{*}>\bar{r}_{-t} \\ 0 & \text { if } \bar{r}_{-t}^{*}<\bar{r}_{-t}\end{array}, I_{\bar{r}_{t}^{*}<\bar{r}_{t}}= \begin{cases}1 & \text { if } \bar{r}_{-t}^{*}<\bar{r}_{-t} \\ 0 & \text { if } \bar{r}_{-t}^{*}>\bar{r}_{-t}\end{cases}\right.$

${ }^{24}$ Note that we assume the funds have the same size, same risk appetite and no automatic reinvestment.
} 
As shown by the equation above, in addition to fundamentals such as monetary policy (determinant of short term interest rates), exchange rate dynamics are driven by financial factors such as stock market performance, speculators' risk appetite and expected market risk. The direction of the mechanism, however, is time-varying and dependent upon the prevailing regime, which is explicitly determined by the status of the HRC, the business cycle, and relative dominance of conflicting reallocations.

\section{Empirical evidence}

\subsection{Data description and variables measure}

Our empirical tests cover the period between 02/1991 and 09/2009. The ending date was the most recent data available at the time this research was conducted. The starting date was chosen for two major reasons. First, as highly-leveraged speculation was uncommon before the 1990s, the mechanism proposed in this paper may be insignificant before this time. Second, governments intervened heavily in the FX market before the 1990s. For example, the Plaza Accord of September 1985 was a concerted effort of governments to depreciate the USD. To halt any further depreciation, the Louver Accord of October 1987 coordinated central banks of major industrialized countries to boost the value of the USD. The market self-corrected for the results of these interventions in a short downturn in 1990. Explaining such exogenous events is not the purpose of our model. We take the period of 02/1991-12/2007 as an in-sample test period, and save the rest of the data (01/2008-09/2009) for out-of-sample tests. ${ }^{25}$ Although the out-of-sample period only covers a short period of less than two years, it contains both downturn and upturn scenarios so that the model's forecast ability can be tested with a richer set of scenarios.

We test our model with five exchange rates: the U.S. Dollar (USD) versus the British Pound (GBP), Canadian Dollar (CAD), Deutsche Mark (DEM), Euro (EUR) and Japanese Yen (JPY). These rates are chosen for several reasons. First, these currencies are freely traded without strict government regulations and capital mobility restrictions, conditions required by

\footnotetext{
${ }^{25}$ Usually, out-of-sample forecasts in exchange rate research are based on rolling regressions and only forecast one period ahead. Since our theory segments the whole data period into different scenarios with explicit regime switches, the rolling regressions, which essentially report moving average results, cannot accurately reflect the forecast accuracy of our model. Instead, our forecasting exercise is to use in-sample estimated parameters to forecast all future periods in the out-of-sample period. To obtain reliable parameter estimates for various scenarios, we need to select a long in-sample period. This is the reason why our out-of-sample period is relatively short compared to similar researches.
} 
the environment assumed in our model. Second, these currency pairs are the most traded currency pairs in the world and attract many institutional speculators. Third, they are typical and representative: the CAD represents commodity currencies such as the Australian Dollar and New Zealand Dollar; before the introduction of the Euro, the DEM represented other major European currencies (e.g. the French Franc and Swiss Franc); since its launch, the Euro has shared the dynamics of other major European currencies such as the Swiss France, etc. The dynamics of the GBP and JPY are unique.

We test at the monthly horizon. Longer horizons (e.g. quarterly) lead to difficulty in obtaining reliable statistics in each scenario due to insufficient observations. Shorter horizons (e.g. daily) suffer from the unavailability of high frequency data for variables such as dealers' risk appetite.

The dependent variable - exchange rate return - is calculated as the log differential of spot exchange rates, which are obtained from OECD Stats. Despite their quote tradition, all rates are converted into the dollar rates of foreign currencies to be compatible with our theoretical framework. Several relatively new explanatory variables are proposed in our paper. The first is the change in the interest rate differential (not the interest rate differential per se), which we measure by obtaining monthly short-term (3-month) interest rates from OECD and calculating the first order difference of the differential. The second subfigure of figures (3) through (7) show the dynamics of the interest rate differential for each currency pair.

The second explanatory variable is the change in stock market expected cross risk premium (i.e. the change in the difference between the expected stock return in the HRC country and the interest rate in the other country). Stock return forecast models are extensive, but no agreement is reached on the optimal one. Even simple historical stock premium mean, as shown by Goyal and Welch (2008), can outperform many popular predicators in rolling outof-sample forecast. So we just use an exponential moving average to estimate expected stock returns for simplicity. We set the expected stock return of the next period as the value of the exponential moving average of the previous twelve periods (a 1-year moving-window). Then, we subtract the interest rate of the low-return currency from the previously calculated values to obtain a monthly cross risk premium, and the first order difference the premium represents this explanatory variable. Actual monthly stock returns are calculated from each country's stock index, which are extracted from OECD.

The third explanatory variable is risk appetite. As suggested by Adrian, Etula, and Shin 
(2009), a good proxy for risk appetite is the leverage of financial institutions because these institutions increase their leverage when they are more risk-loving and de-leverage (either voluntarily or forcibly) otherwise. ${ }^{26}$ Meanwhile, financial institutions adjust leverage mainly through Repo - a popular money market instrument in the "Shadow Banking" system. Consequently, risk appetite can also be approximated by the growth rate of Repo. In fact, leverage and Repo not only reflect risk appetite but also liquidity. Leverage data are originally calculated from all primary dealers (including both domestic and foreign banks) at quarterly frequency. Repo data are originally at weekly frequency and cover all financial institutions including hedge funds in the U.S. market. Both data sets are obtained from the New York Fed. ${ }^{27}$ We transform the original data sets to have monthly frequency so as to be compatible with our tests (linear interpolation is implemented to disaggregate the leverage data, while a simple average is used to aggregate the Repo data). Figure (1) shows the dynamics of leverage and Repo. According to the figure, leverage and Repo are generally consistent after 1995, but show inconsistency before 1995. Since Repo data is more general than leveraged data (it covers hedge funds while leveraged data does not), we use Repo to measure risk appetite in the event the two measures conflict.

The fourth explanatory variable is change in equity. Change in equity for financial institutions can be either caused by addition/withdrawal of capital or by changes in the price of invested assets. The latter - a buy and hold scenario - does not cause transactions in the FX market, and, if we directly used funds' change in equity, would ensure our model suffered from an endogeneity problem. Instead, we propose using non-farm payroll growth to measure equity change based on the rationale that increasing (decreasing) income leads to the injection (withdrawal) of capital to (from) mutual/hedge funds. Payroll data are extracted from the St. Louis Fed's Website and can be seen from the third subfigure of figure (1).

Finally, we use the VIX to represent expected stock risk. At the beginning of each month, the value of the VIX is extracted from Yahoo!Finance, and the resulting data vector is plotted in the fourth subfigure of figure (1). A good proxy for expected exchange rate risk would be from the currency option, but this data is not commonly available. An alternate measure, GARCH estimated exchange rate risk, is highly correlated with exchange rate change. Using

\footnotetext{
${ }^{26}$ Some recent papers also suggest to use TED or VIX as the proxy. However, an increase in TED can be caused by increasing risk, not just an increasing degree of risk aversion. Similarly, the VIX, option implied stock volatility, only reflects expected risks, not risk appetite. Therefore it could be misleading to use these two variables as the proxy of risk appetite.

${ }^{27}$ We thank Tobias Adrian for kindly providing these data.
} 
such estimated risk in the test could be tropicalized by the endogeneity problem. We decide not to include exchange rate risk in our testing.

One common concern for measures of risk appetite, equity change and expected stock risk is whether domestic and foreign measures are consistent. In general, these variables are correlated with business cycles and advanced countries share similar cycles. ${ }^{28}$ Hence, we assume domestic and foreign measures are consistent for these variables.

\subsection{Scenario identification}

As suggested by our model, the direction in which proposed explanatory variables drive the exchange rate is time-varying, but can be specified by HRC indicators $\left(I_{i_{t}^{*}>i_{t}}, I_{\bar{r}_{t}^{*}>\bar{r}_{t}}, I_{\bar{r}_{t}^{*}<\bar{r}_{t}}\right)$ and the relative position of each asset class (reflected by $W_{B^{*}}, W_{S^{*}}$ and $W_{S}$ ). This section introduces the methodology we use to determine the value of these indicators and weights.

The high-return-currency in the money market, which determines the value of $I_{i_{t}^{*}>i_{t}}$, can be determined simply by the sign of the interest rate differential, which is shown in the second subfigure of figures (3) through (7). To determine the values of $I_{\bar{r}_{t}^{*}>\bar{r}_{t}}$ and $I_{\bar{r}_{t}^{*}<\bar{r}_{t}}$, (i.e. stock market scenario identification), we need to first locate market downturn periods, defined as periods with negative expected stock returns. We use the moving average method introduced in the previous section to calculate expected U.S. stock returns and identify the downturn accordingly. ${ }^{29}$ Figure (2) identifies the following downturn periods: 04/1994-01/1995 (the Peso crisis and tightening monetary policy in the U.S.), 10/1998-11/1998 (the credit crisis caused by the bankruptcy of Long Term Capital Management(LTCM)), 04/2001-09/2002 (the dot com bubble burst and terrorist attack), and 01/2008-02/2009 (the subprime mortgage crisis and subsequent economic recession). ${ }^{30}$

The HRC in the stock market is defined as the currency whose country's stock indices have higher return. Higher return is usually associated with higher risk, so stock price in the HRC country should gain higher returns during boom periods and suffer larger losses during economic busts. In this sense, if the foreign currency is the HRC, its country's stock index should increase (decrease) faster than the U.S. counterpart in good (bad) times. Accordingly, if

\footnotetext{
${ }^{28}$ In the 1990s, Japan had a very different business cycle than the other countries. We will address this issue when we examine JPY/USD specifically.

${ }^{29}$ Except for Japan during the 1990s, stock markets across the major countries share the similar fluctuation patterns. Thus, we determine market downturn periods solely based on U.S. stock performance.

${ }^{30}$ Due to the moving average method we used, there is a lag between actual and the identified downturn periods. This minor inconsistency is the price we pay to avoid criticisms that our methodology is ad hoc.
} 
we regress logged values of foreign stock prices $\left(p_{t}^{S^{*}}\right)$ on logged values of American stock prices $\left(p_{t}^{S}\right)$ with a non-zero constant, the slope should be significantly greater (less) than one. Despite sound intuition, the validity of this test is not immediately clear as both stock price indexes are non-stationary. Preliminary data examination and extensive literature suggest that foreign and domestic indexes are often driven by common stochastic factors and therefore cointegrated. This property ensures that while OLS estimation is not spurious, OLS predicted standard errors are unreliable. Instead, we use the Stock-Watson cointegration regression written below:

$$
\log \left(p_{t}^{S^{*}}\right)=\alpha+\beta \log \left(p_{t}^{S}\right)+\sum_{j=-k_{1}}^{+k_{2}} \gamma_{j} \Delta \log \left(p_{t, j}^{S}\right)+\epsilon_{t}
$$

where $\Delta$ represents taking a first order difference, and $k 1$ and $k 2$ denote leads (future) and lags (past) that are equated and selected using AIC. The advantage of this specification is that its OLS estimator is super consistent and its confidence interval can be calculated with a normal t-distribution by using heteroscedasticity and serial correlation consistent standard errors.

To show the dynamics of $\beta$ over time and avoid criticism that the methodology is ad hoc, we conduct such a regression with a window period of two-years before each month. An immediate problem with this setup is that sample bias could arise in the cointegration regression due to the short window period. To overcome the problem, we follow the bootstrap method proposed by Chang, Park, and Song (2006) to estimate the coefficient confidence intervals. The results are displayed in the first subfigure of figures (3) through (7), in which the two dashed lines indicate the $95 \%$ confidence interval for $\beta$.

In these figures, as noted before, $\beta$ significantly above (below) one suggests the foreign currency (USD) to be the HRC. If the null hypothesis $(\beta=1)$ cannot be rejected, implying no significant difference between the two countries stock return, financial institutions buy either domestic stocks or the money market HRC country's stocks and finance their purchases with the money market low return currency. As only the latter trade involves FX transactions, the stock market HRC is consistent with the money market HRC in this scenario.

Order flows generated by bond and stock market reallocation can conflict, in which case our model suggests the dominating factor to be determined by the weight of each asset contained in portfolios (i.e. $2 W_{B^{*}}$ and $W_{S^{*}}\left(W_{S}\right.$ if USD is stock HRC)). The relative relationship between the weights can be examined by comparing the following Seemingly Sharpe Ratios (SSR): 


$$
2 \frac{\left|i_{t}^{*}-i_{t}\right|}{\sigma_{e, t}^{2}} \text { and } \frac{\left|\bar{r}_{t}^{*}-i_{t}\right|}{\sigma_{e, t}^{2}+\sigma_{s^{*}, t}^{2}}\left(\frac{\left|\bar{r}_{t}-i_{t}^{*}\right|}{\sigma_{e, t}^{2}+\sigma_{s, t}^{2}}\right)
$$

where $\sigma_{e, t}^{2}, \sigma_{s^{*}, t}^{2}$ and $\sigma_{s, t}^{2}$ are estimated through corresponding GARCH specifications, and $\bar{r}_{t}^{*}$ and $\bar{r}_{t}$ are foreign and domestic expected stock returns calculated by the moving average method respectively. We calculate these ratios at a monthly frequency but with a quarterly horizon. ${ }^{31}$ The fifth subfigure of figures (3) through (7) show the dynamics of the ratios for each currency pair.

In summary, scenario identification basically involves three steps: the money market, the stock market, and, in the event the previous two markets suggest differing HRCs, the dominating market between the two. In these steps, the money market scenario is the most distinct (most easily identifiable), followed by the stock market downturn scenario, the HRC in the stock market scenario, and finally the dominating market scenario. We follow such a priority to separate periods. For each currency pair, in addition to the figures noted above, tables I through $\mathrm{V}$ also present specific information needed to identify scenarios.

\subsection{Regression specification}

The regression specification used in our tests is below:

$$
\begin{aligned}
& \Delta e_{t+1}=\beta_{1} I D C_{t}+\beta_{2} R P C_{t}+\beta_{3} R A C_{t+1}+\beta_{4} E q u i t y C_{t+1}+\beta_{5} R i s k C_{t}+\epsilon_{t+1} \\
& I D C_{t}=\Delta\left(i_{t}^{*}-i_{t}\right) \\
& R P C_{t}= \begin{cases}\Delta\left(\bar{r}_{t}^{*}-i_{t}\right) & \text { if } I_{\bar{r}_{t}^{*}>\bar{r}_{t}}=1 \\
-\Delta\left(\bar{r}_{t}-i_{t}^{*}\right) & \text { if } I_{\bar{r}_{t}^{*}>\bar{r}_{t}}=0\end{cases} \\
& R A C_{t}= \begin{cases}\Delta R A_{t} & \text { if }\left[2 W_{B^{*}} I_{i_{t}^{*}>i_{t}}+\left(I_{\bar{r}_{t}^{*}>\bar{r}_{t}} W_{S^{*}}-I_{\bar{r}_{t}^{*}<\bar{r}_{t}} W_{S}\right)\right]>0 \\
-\Delta R A_{t} & \text { if }\left[2 W_{B^{*}} I_{i_{t}^{*}>i_{t}}+\left(I_{\bar{r}_{t}^{*}>\bar{r}_{t}} W_{S^{*}}-I_{\bar{r}_{t}^{*}<\bar{r}_{t}} W_{S}\right)\right]<0\end{cases} \\
& \text { Equity }_{t}= \begin{cases}\Delta \text { Payroll }_{t} & \text { if }\left[2 W_{B^{*}} I_{i_{t}^{*}>i_{t}}+\left(I_{\bar{r}_{t}^{*}>\bar{r}_{t}} W_{S^{*}}-I_{\bar{r}_{t}^{*}<\bar{r}_{t}} W_{S}\right)\right]>0 \\
-\Delta \text { Payroll }_{t} & \text { if }\left[2 W_{B^{*}} I_{i_{t}^{*}>i_{t}}+\left(I_{\bar{r}_{t}^{*}}>\bar{r}_{t}\right.\right. \\
\left.\left.W_{S^{*}}-I_{\bar{r}_{t}^{*}<\bar{r}_{t}} W_{S}\right)\right]<0\end{cases} \\
& \text { RiskC } C_{t}= \begin{cases}\Delta V I X_{t} & \text { if } I_{\bar{r}_{t}^{*}>\bar{r}_{t}}=1 \\
-\Delta V I X_{t} & \text { if } I_{\bar{r}_{t}^{*}>\bar{r}_{t}}=0\end{cases}
\end{aligned}
$$

where $\Delta e_{t+1}$ is the exchange rate return (the log differential of the spot rate written as the dollar rate per foreign currency), $I D C_{t}$ is the change in interest rate differential (first order difference of the interest rate differential), $R P C_{t}$ represents the change in stock market risk premium (first order difference of the gap between the expected stock return of the HRC country and the interest rate of the other country), $R A C_{t}$ is the change in risk appetite (log differential of leverage

\footnotetext{
${ }^{31}$ Preliminary tests show that results at the one month horizon are too volatile to clearly discern a pattern.
} 
(post-1995) or outstanding Repo (pre-1995)), RiskC $C_{t}$ is the change in expected stock market risk (log differential of VIX), and $E q u i t y C_{t+1}$ is the change in equity capital (log differential of U.S. non-farm payroll). The condition that $\left[2 W_{B^{*}} I_{i_{t}^{*}>i_{t}}+\left(I_{\bar{r}_{t}^{*}>\bar{r}_{t}} W_{S^{*}}-I_{\bar{r}_{t}^{*}<\bar{r}_{t}} W_{S}\right)\right]>0(<0)$ ensures that the foreign currency (the USD) is the HRC in both markets or the dominant market given conflict. Condition $I_{\bar{r}_{t}^{*}>\bar{r}_{t}}=1(=0)$ ensures that the stock market HRC is the foreign currency (the USD). Again, note that during downturn scenarios the values of $I_{\bar{r}_{t}^{*}>\bar{r}_{t}}$ and $I_{\bar{r}_{t}^{*}<\bar{r}_{t}}$ are determined by the stock market performance prior to the downturn.

In the regressions above, we would like to emphasize that exchange rate return is the change in the exchange rate between the next month and the current month. Payroll growth and change in risk appetite are calculated using the same period because both should be exogenous to exchange rate dynamics. ${ }^{32}$ All other explanatory variables, which may be endogenously interacted with exchange rate return, are defined as changes between the current month and the previous month. Thus, our regression should be free from the endogeneity problem.

In all the regressions, the correct sign on the coefficients of all explanatory variables except stock risk change is positive. Since the model suggests that higher risk leads to a decreased holding of HRC assets, the correct sign for risk change should be negative. As it is well-known that exchange rate return has time-varying volatility, we use Newey-West heteroscedasticity and serial correlation consistent standard errors to calculate t-statistics. Unsurprisingly, some of the explanatory variables are highly correlated in some periods, and this multicollinearity problem could jeopardize our results. As a robustness test, we individually test each significant variable to report its significance.

To show the proposed relationship more clearly, we use the Hodrick-Prescott filter to remove noise from the data. Unlike the filter's typical use in macroeconomics - to detrend raw data so as to obtain the business cycle (medium frequency component) - our purpose of using the filter is to preserve as much variation as possible in the data while eliminating some noise (the high frequency component). In this sense, we do not follow the suggestions of the literature ${ }^{33}$ and use a very small smooth parameter of $5 .{ }^{34}$ The third subfigure of figures (3) through (7) show

\footnotetext{
${ }^{32}$ Strictly speaking, additional equity investment (or withdrawal) and exchange rate change are also interacted, and using the direct measure is subject to the endogeneity problem. However, we use payroll growth as the proxy in the paper and payroll growth is hardly affected by exchange rate change. Hence, we use the contemporaneous value of payroll change as the change in equity in the regression.

${ }^{33}$ The literature usually suggests a smooth parameter of 14400 for monthly data, 1600 for quarterly data and 7 for annual data (based on some econometric estimation).

${ }^{34}$ The choice of the smooth parameter is arbitrary, but addtional tests (not reported in this paper) show that our empirical results are robust for different small parameters.
} 
both raw (blue solid line) and filtered (red dash line) exchange rates, and we can see almost all major variation is maintained in the filtered data. Intuitively, filtered (de-noised) data represent medium and long term components of the raw data, and the portion of the original data filtered out (noise) reflects the short term component. Conducting the regressions on the de-noised and noise parts of the data separately would tell us how robust our proposed mechanisms are for different components of exchange rate dynamics.

Finally, preliminary tests show that the coefficients of the regression equation are timevarying. Furthermore, what explanatory variables are significant and dominant also vary in different regimes. To accommodate these non-linearities, instead of a single regression, we run the test separately in each regime for each currency pair.

\subsection{Regression results}

Unlike most studies in this field that present supporting evidence based upon either large panel data regressions or a limited set of countries and periods, or incorporate a majority of countries but ignore existing inconsistencies, our evidence is currency-specific and periodspecific. We organize this section accordingly. For each currency pair, regression results are reported in one table (tables I through V) accompanied by a figure (figures (3) through (7)).

\subsubsection{Deutsche Mark}

Between 02/1991 and 03/1994, the large amount of money injected into East Germany due to reunification led to concerns about inflation and resulted in an increasing interest rate in Germany. During the same period, the U.S. continued to maintain a post-recession economically stimulating low interest rate. This created a substantial and stable profit margin for the carry trade. As shown in figure (3), exchange rate dynamics during this period closely follow the bell-shape of interest rate differential dynamics, an observation confirmed by the empirical tests reported in table I. Additionally, stock risk premium change is found to be significant with correct signs in both direct and de-noised tests.

In the next period, 04/1994 through 01/1995, there was a stock market downturn. If the mechanism prevailing in the previous period continued, a decreasing interest rate differential would lead to the depreciation of the DEM . However, as this is a downturn scenario, financial firms should attempt to dump stocks of the previous HRC - the USD - causing the DEM to appreciate. Actual exchange rate dynamics, as shown in figure (3), confirm such a mechanism, 
although we do not run the regression due to limited sample size.

From early 1995, the Fed's tightening monetary policy and the booming IT industry in the U.S. made the USD the HRC in both money and stock markets. ${ }^{35}$ Therefore, Dollar assets were more attractive to foreign investors, causing the USD to appreciate. This intuition is supported by results from the direct test: both interest rate differential change and stock risk premium change are significant and robust with correct signs. In addition, the significantly negative coefficient of stock risk change suggests that decreasing expected risk further contributed to the appreciation of the dollar in this period.

\subsubsection{British Pound}

To maintain a stable exchange rate against the DEM, monetary policy in the United Kingdom closely followed the German counterpart during the early 1990s. After leaving the Exchange Rate Mechanism (ERM) in September 1992, British monetary policy had been conducted within an inflation targeting framework, while contemporaneous American monetary policy emphasized more on output and employment. As a result, the interest rate in the UK was higher than that in the US for most of our sample period, which can be seen from figure (4). Such a stable interest rate differential incentivized the carry trade, and, unsurprisingly, table II shows that change in interest rate differential is highly significant and robust with correct sign for the periods between 02/1991 and 05/2000 and 10/2002 and 12/2007.

With the exception of two short downturns from 04/1994-01/1995 and 10/1998-11/1998, the USD was the stock market HRC for the most of the period between 02/1991 and 05/2000. In contrast, from 10/2002 to 12/2007, the GBP was the stock market HRC except for a short period around 2005. The regressions show that stock risk premium change contributed significantly to medium and long term exchange rate dynamics during the first period and to overall dynamics in the second period.

The common feature of the downturn periods 04/1994-01/1995, 10/1998-11/1998 and 04/200109/2002 is that the USD was the stock market HRC before the downturns. Direct tests on the pooled sample find risk appetite to be significant and robust with correct sign. The de-noised test further reveals that stock risk premium also accounts for medium and long term dynamics. Intuitively, when the downturn begins and stock prices and risk appetite fall, fund managers

\footnotetext{
${ }^{35}$ The stock index rolling regression cannot reject the null hypothesis that the beta equal one for the second half of the period. In this case, as analyzed before, the HRC in the stock market should be consistent with the money market HRC i.e. the USD.
} 
start dumping previously held stock market HRC - the USD - leading to the appreciation of the GBP. This pattern can be seen more clearly from figure (4) for all three periods.

\subsubsection{Canadian Dollar}

As shown by figure (5), the CAD was the HRC in the money market from 02/1991-02/1996. In the same period, the USD was the stock market HRC except for a single downturn between 04/1994 and 01/1995. The dominance of the stock market during this five-year period, as illustrated by the SSR figure, suggests that the USD is the overall HRC. A de-noised test finds risk appetite to be significant with correct sign. The direct and noise tests report interest rate differential change to be significant but with incorrect sign, implying that money market reallocation would drive exchange rate in the opposite direction. Such a conflict can be reconciled by the dominance of stock reallocation.

Before the downturns of 04/1994-01/1995 and 10/1998-11/1998, the USD was the stock market HRC. According to our model, investors should sell USD stocks during these periods, causing the CAD to appreciate. This pattern can be seen from figure (5), although no regressions are conducted due to limited sample size.

From 03/1996-06/1999, Canada did not sustain the economic growth of its southern neighbor. This is reflected in the stock market, where the US market had higher returns and, correspondingly, was the stock market HRC. The Fed's tightening monetary policy post-1995 also made the USD the HRC in the money market. As risk appetite increased, speculators held more dollar assets, which drove the dollar up. ${ }^{36}$ This mechanism is supported by both the direct and de-noised tests reported in table III.

From $07 / 1999$ - 03/2001, the USD continued to be the HRC in the money market. In the stock market, however, a significant regime switch occurred. In this period, the Canadian stock market grew faster than the American market, as shown in figure (5), because investors were concerned with bubbles in American stocks. Thanks to rapidly increasing oil prices, Canada, a major oil exporter, had higher stock returns than the US in the late 2000s. To combat the housing market bubble, the Fed started raising interest rates in 2005. The period of 01/2005$12 / 2007$ thus had the same HRC status as the period of $07 / 1999-03 / 2001$. The tests on the combined sample find stock risk premium change to be significant with correct sign. In addition,

\footnotetext{
${ }^{36}$ When risk appetite increases, American funds buy dollar stocks as well, but such a transaction does not involve FX transactions.
} 
payroll growth and interest rate differential change return significant and correct signs in denoised and noise tests respectively.

The burst of the dot com bubble led to a market downturn between 04/2001 and 09/2002. Unlike previous downturns (i.e. 04/1994-01/1995 and 10/1998-11/1998), the CAD was the stock market HRC before this downturn. Accordingly, investors would dump CAD assets, causing the USD to appreciate. This is the opposite of the dynamics in the previous two downturns and can be seen clearly from figure (5).

Loose interest rate policy in the U.S. after the 2001-2002 downturn made the CAD the money market HRC from 10/2002-12/2004. The rolling regression of stock indices does not show a significant difference between the expected returns of the two countries stock markets. As analyzed previously, in this case the CAD (the money market HRC) should be the stock market HRC. Direct tests find interest rate differential change and stock risk premium change to be significant and supportive of our model with combined explanatory power of $26 \%$. De-noised and noise tests further suggest that the former variable mainly affects short term dynamics while the latter affects medium and long term dynamics.

\subsubsection{Euro}

From its launch in 1999 until 04/2001, as shown by figure (6), the EUR was the HRC in the stock market and the USD was the HRC in the money market. SSRs suggest the dominance of the stock market and the EUR to be the overall HRC. Direct and de-noised tests all find payroll change to be significant but with incorrect sign. According to our model, as payroll increases, more funds should be invested in European stocks and the Euro should appreciate. This is not corroborated by the observed data. In the entire set of empirical tests of our model, this is one of a handful of inconsistencies, and could be the result of exogenous forces such as investors' uncertainty about the new unified European currency or the conversion of black money in Eastern Europe from the DEM to the USD (Sinn and Westermann (2001)).

Before the dot com bubble burst in 2001, the USD appreciated relative to the EUR, implying that European funds were buying dollar assets. In turn, this implies that the USD was actually the stock market HRC before the downturn, contrary to the suggestion of our rolling regression. As the downturn started, investors needed to dump dollar assets, causing the depreciation of the USD in general, which can be seen from figure (6). The direct and denoised tests confirm such a mechanism: stock risk premium change is significant with correct sign. 
From 10/2002-12/2004, loose monetary policy in the U.S. made the EUR the HRC in the money market. Meanwhile, the rolling regressions shown in figure (6) suggests the EUR to be the stock market HRC during the same period. As the global economy recovered, increasing stock market risk premiums and increasing risk appetite generated buy orders toward Euro assets, causing the appreciation of the Euro. These mechanisms are supported by regression results in table IV and illustrated in figure (6).

At the start of 2005, increased concerns that the post-2001 low interest rate policy of the Fed would cause inflation led the U.S. to tighten interest rates, widening the gap with European interest rates. In contrast, although the Euro zone continued to outperform the U.S. in the stock market, the stock risk premium as shown by figure (6) was quite stable. As a result, bond reallocation in this period should dominate stock reallocation. Regression results show that interest rate differential change is the only significant coefficient with correct sign.

\subsubsection{Japanese Yen}

Between 02/1991 and 09/1993, a growing American stock market was juxtaposed with a collapsing Japanese market. Our model characterizes a market downturn with the dumping of risky assets of the previous HRC, which is the USD according to the first subfigure of figure (7). However, as the American stock market was still on an uptrend, this period was not a downturn scenario. Nevertheless, due to the burst bubble in the Japanese market, Japanese banks had a liquidity crisis and were forced to reduce their leverage. Decreasing risk appetite was found by the direct test to be significantly associated with the appreciation of the JPY during this period. ${ }^{37}$ Figure (7) combined with the second subfigure of figure (1) can tell a more intuitive story: decreasing leverage forced Japanese banks to sell their Dollar assets, ${ }^{38}$ and thus FX order flow went from the USD to the JPY. This explains the appreciation of the JPY in the early 1990s despite the fact that the Japanese economy was in trouble. ${ }^{39}$

From 10/1993 until 09/1998 (excepting 04/1994 - 01/1995), the Bank of Japan maintained its near-zero interest rate policy, making the USD the HRC in the money market. In this period,

\footnotetext{
${ }^{37}$ In our previous empirical tests, we used outstanding Repo to represent risk appetite before 1995 . We use leverage instead for the JPY to reflect decreasing risk appetites of these Japanese banks. Ideally, we should use the leverage of banks in Japan. Due to the difficulty of acquiring such data, we use the leverage of all primary dealers, including foreign banks, as a proxy.

${ }^{38}$ In the 1980s, due to high economic growth, an increasing trade surplus with the US, and a bubble in Japanese capital markets, Japan accumulated a large amount of dollar assets before its stock market meltdown.

${ }^{39} \mathrm{In}$ fact, the appreciation of the Yen during this period is a puzzling phenomenon which attracts a number of discussions (see Obstfeld (2009)). Our theory and results suggest an alternative explanation.
} 
U.S. stocks grew at rapid pace while the Japanese market experienced several adjustments. As analyzed previously, since the American stock market continued to grow, we do not define the period as a downturn scenario. Direct tests show that the change in stock market risk premium has a significant and robust coefficient with correct sign. De-noised and noise tests further reveal that medium and long term components of exchange rate dynamics are mainly driven by risk appetite, while short term volatility is explained mainly by the change in stock market risk premium.

The periods from 04/1994 - 01/1995 and 10/1998-11/1998 are two downturn periods with similar features (the USD was the money market HRC and the previous stock market HRC). By our model, fund managers would unwind long positions of the USD and close short positions of the JPY, leading to the appreciation of the JPY. This result can be seen clearly from figure (7).

Stock markets recovered quickly after the panic caused by the bankruptcy of the LTCM in 1998. From 12/1998-03/2001, the USD continued to be the money market HRC, but the JPY, according to figure (7), became the stock market HRC. In direct and noise tests, the coefficients for both payroll growth and expected stock risk are found to be significant and robust with correct sign. Direct and de-noised tests on the downturn period from 04/200109/2002 all show the coefficient for change in risk appetite to be significant and robust with correct sign. De-noised tests also report the coefficient for the change in interest rate differential to be significant but with incorrect sign, which can be reconciled by the dominance of stock reallocation as suggested by SSRs.

From $10 / 2002$ to $12 / 2007$, the continuing Japanese near-zero interest rate policy made the USD the money market HRC. Except for a short period between $02 / 2006$ and $08 / 2007$, the rolling regression in the stock market finds no significant difference between the two countries' stock returns, in which case the stock market HRC should be consistent with the money market HRC (i.e. the USD). Although the JPY appeared to be the stock market HRC between 02/2006 and 08/2007, SSRs suggest that money market reallocation dominates stock market reallocation, ${ }^{40}$ leading to an overall HRC during this short period that is consistent with the periods around it. The empirical tests over the entire five-year period show that along with change in risk appetite, the change in interest rate differential appears to be the driving factor

\footnotetext{
${ }^{40}$ The dominance is determined by comparing the money market SSR and the stock market SSR of the HRC, which was the JPY then.
} 
of the exchange rate. This result is consistent with findings reported by Brunnermeier, Nagel, and Pedersen (2008) as well as Gagnon and Chaboud (2007) that the carry trade dominated Yen dynamics during this period.

\subsection{Out-of-Sample forecast}

The out-of-sample forecast in exchange rate research is usually made using rolling regressions and only predicts one period ahead. Since our theory segments the entire data period into different scenarios with explicit regime switches, the rolling regressions, which essentially report moving average results, cannot accurately reflect the forecast accuracy of our model, particularly during regime switches. Furthermore, in contrast with a pure ex ante forecast, whose accuracy is subject to the reliability of both the proposed relationship (the model) and predicted explanatory variables, an ex post forecast predicts the future exchange rate based upon in-sample estimations of parameters and realized future explanatory variables, and its performance is determined solely by the proposed model. Our proposed explanatory variables are almost exclusively financial variables. Given that the current literature still lacks the ability to accurately forecast such variables, our forecasting exercises are ex post simulations for all future periods in the out-of-sample period.

Our empirical results consistently find that the changes in interest rate differential, stock risk premium, and risk appetite are significant and robust variables. Consequently, we only use these three variables in our forecast. First, we identify the scenarios in each out-of-sample period. Then, we substitute values for parameters determined from in-sample estimations during similar scenarios and finally forecast exchange rate return based upon equation (28). We pick the most similar scenarios if the identical scenario cannot be found in the in-sample period. Preference is given to the most recent period when two periods have equivalent scenarios. We only pick significant and robust parameter results, assigning a value of zero if the coefficient is insignificant.

Since $01 / 2008$, the stock market has plunged due to the sub-prime mortgage crisis, a clear downturn scenario. The Federal Reserve responded by reducing American interest rates to historically low levels, making the EUR, CAD and GBP the HRC in the money market relative to the USD. As these currencies were also all the stock market HRC relative to the USD before the downturn, they share the same scenario. Despite the rapid decline of the U.S. interest rate, it remained higher than its Japanese counterpart thanks to the continued near-zero interest rate 
policy of Japan. In the stock market, the USD was the HRC relative to the Yen before the downturn. ${ }^{41}$ Thus, the JPY had a completely different scenario than the other three currencies.

Since the first quarter of 2009, positive economic data have emerged and global stock markets have recovered, suggesting an end to the downturn scenario. Since our data for the new uptrend consists only of 7 observations, rolling regressions of stock indices, which are based on historical data, may not have enough information to accurately identify the stock market HRC. Instead, we set the stock market HRC in the most recent uptrend to be the same as the stock HRC for this period. Accordingly, the GBP, CAD, EUR and JPY all become the stock market HRC. In the money market, foreign countries followed U.S. monetary policy, though not to the same extent, and their currencies remained the HRC in money market (except for the JPY, as noted above).

Table VI shows the parameter values input into the forecast for each currency pair and figure (8) shows the forecast results. As shown by the figure, major turning points in 2008 and 2009 are perfectly predicted by the model. Throughout the out-of-sample period, the GBP, CAD and EUR share similar dynamics. As the global downturn began, investors started dumping predownturn HRC (i.e. GBP, CAD and EUR) assets, causing the dollar to appreciate. Moreover, risk appetite (leverage) decreased rapidly, indicating investors' preference toward the current safe haven currency (i.e. the USD), which contributed further to the appreciation of the USD. As the market recovered, increased risk appetite and positive economic news drove buy orders for the HRC (GBP, CAD and EUR), explaining the observed depreciation of the USD.

Interestingly, the JPY has completely different dynamics for the same time period, an issue greatly under-addressed in the literature. Unlike the other three currency pairs, the USD was the HRC before the downturn. Furthermore, an increasing interest rate differential in favor of the USD since 2005 incentivized a long position in the USD. Thus, as the financial crisis unfolded and funds were forced to de-leverage in 2008, fund managers need to dump USD assets, explaining the depreciation of the dollar relative to the JPY while it simultaneously appreciated against other major currencies. Until early 2009 the interest rate differential between the USD and JPY was nearly zero. Thus, the profit margin of the carry trade had disappeared and stock market reallocation had dominated money market reallocation. Since March 2009, the JPY

\footnotetext{
${ }^{41}$ Despite a short period of 02/2006-08/2007 when the JPY seems to be the stock HRC, for most of the time in the second half of this period (10/2002-12/2007), no significant difference is detected between American and Japanese stock returns, in which case the stock market HRC should be consistent with the money market HRC - the USD.
} 
became the stock market HRC. This places the JPY/USD exchange rate in the same scenario as the other major exchange rates (the foreign currency as the HRC), and, consequently, all four currency pairs share similar dynamics.

\subsection{Comparison with benchmark}

Since the publication of Meese and Rogoff (1983), outperforming a random walk has become the golden standard by which to judge the forecast accuracy of an exchange rate models. A typical test is to calculate the ratio between the mean squared error (MSE) of the structural models and a driftless random walk. A value smaller (larger) than one indicates a better performance of the structural model (random walk). Usually, this ratio is calculated based on an out-of-sample forecast obtained from a rolling regression. Since our theory segments the whole data period into different scenarios with explicit regime switches, the rolling regression method is implausible. Consequently, we only focus on the out-of-sample period (i.e. 01/200809/2009) for our comparison. In this period, there are 21 observations for each exchange rate and 84 in total.

From a practical perspective, correctly forecasting directional changes of the exchange rate with larger forecast error is better than incorrectly predicting directional changes with smaller error. In other words, the MSE criterion should not be the only metric used to judge forecast performance. An alternative evaluation metric would be the direction change ratio - the number of correct predictions of the direction of change over the total number of predictions. A value above (below) 50 percent indicates a better (worse) forecasting performance than a naive model that predicts the exchange rate has an equal chance to go up or down.

Table VII shows the results. Except for the JPY, the MSE ratio of the other three currencies is significantly smaller than one. Furthermore, our model generates a directional change ratio significantly higher than $50 \%$ across all currencies. Overall, we can conclude that an ex post forecast of our structural model is superior to a random walk.

\section{Implication and discussion}

Our model suggests that fundamentals must influence the exchange rate through financial markets. Financial variables that drive exchange rate dynamics are certainly related to fundamentals, but not in a one-to-one mechanical relationship. Information heterogeneity, human 
psychology and irrational behavior can all cause a disconnect between fundamentals and financial variables, especially in the short term. This explains the poor performance of macro models in the short run and also contributes to the well-known disconnect puzzle. Furthermore, the manner in which different financial variables affect the exchange rate varies with regime. Without an explicit structural setup, current regime-switching exchange rate models rely on econometrics to capture this time-variance, often generating unreliable and unintuitive results. Thus, the disconnect puzzle emerges not only because financial variables and fundamentals can diverge, but also because their relationship, if it exists, is time-varying, a property current econometrics-based regime-switching models have difficulties in detecting.

The explicit regime switch proposed by our paper can also reconcile several puzzling results found in related research. Angelo and Paul (2010) argue that the JPY, CHF and DEM are safe haven currencies as they appreciate when the stock market experiences downturns. Their conclusion seemed to hold during the 1990s but is contradicted by the events of 2008. Adrian, Etula, and Shin (2009) suggest that high leverage is followed by the appreciation of the USD. Their conclusion is true for all major currencies during the most recent crisis, but not for the JPY. Furthermore, the unwinding of leverage in 1998 and 1994 all led to the depreciation of the USD. Our research reconciles these inconsistencies with a new mechanism: a switch in the HRC. During the 1990s, the faster-growing U.S. economy made the USD the high-return currency and attracted large foreign investments in dollar assets. When financial crises arrived, usually accompanied with an unwinding of leverage, fund managers had to reduce their position of risky dollar assets, forcing foreign currencies to appreciate. After 2002, the regime changed with major foreign currencies except for the JPY becoming the HRC. Thus, speculators would hold more foreign risky assets during economic boom periods. When forced to reduce leverage due to the credit crisis in 2008, fund managers started dumping these foreign assets, leading to an appreciation of the USD. Due to the Bank of Japan's near-zero interest rate policy, the USD was still the HRC relative to the JPY, explaining the depreciation of the USD relative to the JPY during the 2008 downturn.

Our research also sheds insight into the carry trade, a phenomenon generalized as the reallocation of money market assets in our model. The carry trade has been shown to consistently generate excessive returns. Instead of treating these returns as a pre-condition like Òscar Jordà and Taylor (2009) and Clarida, Davis, and Pedersen (2009), our paper suggests that the arbitrage behavior per se drives the exchange rate in the direction contributing to the excessive 
return. Such a self-fulfilling view is in agreement with Plantin and Shin (2008) and Gagnon and Chaboud (2007). Furthermore, we show with convincing evidence that the currency with the higher interest rate does not necessarily appreciate. Instead, the driving force behind the exchange rate is the change in the interest rate differential, not the sign of the differential. The fact that the carry trade mechanism only explains certain currencies during certain periods can be reconciled with the switching dominance between stock market reallocation and money market reallocation proposed in our paper.

The essential idea of our model, that exchange rate dynamics are directly related to financial market structure and can be explained by financial institutions' portfolio reallocation behavior, is consistent with international portfolio rebalance studies such as Pavlova and Roberto (2007) and Hau and Rey $(2004,2006)$. A seemingly conflicting conclusion between our model and Hay and Rey $(2004,2006,2008)$ is that they argue increasing foreign stock returns in excess of U.S. stock returns leads to depreciation of the foreign currency, while our model suggests that increasing expected return of foreign stocks (if the foreign currency is the HRC) leads to the appreciation of the foreign currency. In fact, these two conclusions are not necessarily contradictory. Their work focuses on what would happen after returns to foreign stocks increase while ours focuses on the effect of investors expecting increased return to foreign stocks.

Limitations of our model need to be noted. The model works well only when a currency's actual market environment is consistent with the model's setup, that is, the currency is freely traded with few regulations, interventions and capital mobility restrictions. In this sense, our model cannot explain exchange rate dynamics for currencies (or periods) that are heavily intervened (e.g. major currencies in the 1980s), currencies that do not attract sufficient institutional speculations (e.g. Indian Rupee), currencies that are not traded freely (e.g. Chinese Yuan), and currencies that are strictly managed (e.g. Hong Kong Dollar). As we show in empirical tests, the exchange rate is determined by multiple factors through multiple channels in multiple regimes that are all time-varying. Although we believe the model described in this paper accurately reflects the way the market actually worked during the 1990s and 2000s, it is likely the model will stop working sometime in the future as changes in the microstructure of financial markets create new scenarios (e.g. high-leverage speculation is strictly regulated, financial institutions follow different risk management regulations, etc.). In this sense, this catch-me-if-you-can game will continue in the field of exchange rate determination, probably forever. 


\section{Conclusion}

This paper links exchange rate dynamics with the dynamic optimal portfolio reallocation behavior of financial institutions. Exchange rate dynamics are thus based directly upon the financial market structure as opposed to traditional macroeconomic variables. This paper finds that changes in interest rate differentials, stock market risk premiums, and risk appetites are significantly associated with exchange rate dynamics, but the relationship between these variables and the exchange rate varies in different regimes. Regime switches can be caused explicitly by the change of HRC status, the business cycle, and the dominance of conflicting assets reallocations. Even within the same regime, dominating variables vary across currencies and time.

The mechanism based upon profit-seeking behavior of financial firms, the explanatory variables, and the explicit regime-switch proposed by our paper are novel and shown to be critical to explain exchange rate dynamics. Incorporating these features should be able to improve the explanatory power and forecast accuracy of exchange rate models on any track, macro or micro, theoretical or empirical. Specifically, adding behavioral factors and explicit regime switches into current fundamentals-driven exchange rate models can help solve the well-known disconnect puzzle. Further examination on the role of risk appetite in exchange rate dynamics can help clarify what exactly drives currency "risk premium," especially for individual currency pairs.

The supporting evidence presented in this paper is based on data collected directly from the market on an aggregate level. It would be helpful for future research to use micro-level data, such as hedge funds portfolio allocation data, to test our proposed mechanisms.

\section{References}

Adrian, T., E. Etula, and H. S. Shin (2009). Risk appetite and exchange rates. Federal Reserve Bank of New York Staff Report no. 361.

Angelo, R. and S. Paul (2010). Safe haven currencies. Review of Finance, Forthcoming.

Bacchetta, P. and E. V. Wincoop (2009). On the unstable relationship between exchange rates and macroeconomic fundamentals. NBER working paper 15008.

Brunnermeier, M., S. Nagel, and L. Pedersen (2008). Carry trades and currency crashes. NBER Working Paper No. 14473.

Carlson, A. J., C. M. Dahl, and C. L. Osler (2008). Short-run exchange-rate dynamics: Theory 
and evidence. Working paper.

Chang, Y., J. Y. Park, and K. Song (2006). Bootstrapping cointegrating regressions. Journal of Econometrics 133, 703-739.

Cheung, Y., M. D. Chinn, and A. Pascual (2005). Empirical exchange rate models of the nineties: Are any fit to survive? Journal of International Money and Finance 24, 11501175 .

Cheung, Y. W. and M. D. Chinn (2001). Currency traders and exchange rate dynamics: A survey of the US market. Journal of International Money and Finance 20, 439-471.

Clarida, R., J. Davis, and N. Pedersen (2009). Currency carry trade regimes: Beyond the fama regression. Journal of International Money and Finance 28, 1375-1389.

Clark, P. and R. MacDonald (1999). Exchange rates and economic fundamentals: A methodological comparison of beers and feers. Equilibrium Exchange Rates, edited by J. Stein.and R. MacDonald, 285-322.

DeGregorio, J. and H. Wolf (1994). Terms of trade, productivity, and the real exchange rate. NBER Working Paper $480 \%$.

Dunne, P., H. Hau, and M. Moore (2010). International order flows: Explaining equity and exchange rate returns. Journal of International Money and Finance 29, 358-386.

Engel, C., N. Mark, and K. West (2007). Exchange rate models are not as bad as you think. NBER Working Paper No. 13318.

Engel, C. and K. West (2005). Exchange rates and fundamentals. Journal of Political Economy $113,485-517$.

Engel, C. and K. D. West (2010). Global interest rates, currency returns, and the real value of the dollar. American Economic Review 100, 562-567.

Evans, M. and R. K. Lyons (2002). Order flow and exchange rate dynamics. Journal of Political Economy 110, 170-180.

Evans, M. and R. K. Lyons (2005). Meese-Rogoff redux: Micro-based exchange-rate forecasting. American Economic Review Papers and Proceedings 95, 405-414.

Evans, M. and R. K. Lyons (2007). Exchange-rate fundamentals and order flow. NBER Working Paper 13151.

Evans, M. and R. K. Lyons (2008). How is macro news transmitted to exchange rates? Journal of Financial Economics 88, 26-50.

Gagnon, J. and A. Chaboud (2007). What can the data tell us about carry trades in Japanese Yen? International Finance Discussion Paper 899, Federal Reserve Bank.

Goyal, A. and I. Welch (2008). A comprehensive look at the empirical performance of equity premium prediction. Review of Financial Studies 21, 1455-1508.

Hau, H. and H. Rey (2004). Can portfolio rebalancing explain the dynamics of equity returns, equity flows, and exchange rates? American Economic Review 94, 126-133. 
Hau, H. and H. Rey (2006). Exchange rate, equity prices and capital flows. Review of Financial Studies 19, 273-317.

Hau, H. and H. Rey (2008). Global portfolio rebalancing under the microscope. NBER Working Papers 14165.

Lane, P. R. (2001). The new open economy macroeconomics: A survey. Journal of International Economics 54, 235-266.

Meese, R. A. and K. Rogoff (1983). Empirical exchange rate models of the seventies: Do they fit out of sample? Journal of International Economics 14, 3-24.

Obstfeld, M. (2009). Time of troubles: The Yen and Japan's economy, 1985-2008. Working paper.

Obstfeld, M. and K. Rogoff (1995). Exchange rate dynamics redux. Journal of Political Economy 103, 624-660.

Pavlova, A. and R. Roberto (2007). Asset prices and exchange rates. Review of Financial Studies 20, 1139-1180.

Plantin, G. and H. S. Shin (2008). Carry trades and speculative dynamics. London Business School and Princeton University working paper.

Rossi, B. (2005). Testing long-horizon predictive ability, and the Meese-Rogoff puzzle. International Economic Review 46, 61-92.

Sarno, L. and M. P. Taylor (2002). The economics of exchange rates. Cambridge Press.

Sarno, L. and G. Valente (2009). Exchange rates and fundamentals: Footloose or evolving relationship? Journal of the European Economic Association 7, 786-830.

Sinn, H.-W. and F. Westermann (2001). Why has the Euro been falling? an investigation into the determinants of the exchange rate. NBER Working Paper No. 8352.

Òscar Jordà and A. M. Taylor (2009). The carry trade and fundamentals: Nothing to fear but fear itself. NBER working Paper 15518. 


\section{Table I: DEM/USD}

Money market HRC (MHRC) is the currency with higher interest rate. The USD (foreign currency) is defined as Stock market HRC (SHRC) if slope obtained in Stock-Watson conintegration regression of $\log$ foreign and domestic stock index is significantly lower (higher) than one. Stock market downturns are periods when expected returns turn negative, where the expected stock returns are calculated based on moving average method. The Seemingly Sharpe Ratios are used to determine the dominance of conflicting reallocations. Numbers reported under each variable are estimates and corresponding t-statistics. Estimates and t-statistics of robust tests are reported right next to the original results. Robust test is conducted individually when multiple variables are significant. All t-statistics are calculated with NewyWest heteroscedasticity and serial correlation-consistent standard errors. The results in bold and blue indicate supporting evidence of the model, while red and italic are opposing evidence. The percentage number in the denoised regression means how much variation of exchange rate the filtered data account for. The notes also apply to the similar tables of the other currencies.

\begin{tabular}{|c|c|c|c|c|c|c|c|c|c|c|c|}
\hline \multicolumn{12}{|c|}{ Panel A: periods that are tested and reported } \\
\hline $\begin{array}{l}\text { Period } \\
\text { (\# of obs.) }\end{array}$ & \multicolumn{2}{|c|}{$\begin{array}{l}\text { Scenario } \\
\text { identification } \\
\text { information }\end{array}$} & $\begin{array}{l}\text { Interest rate } \\
\text { differential change }\end{array}$ & $\begin{array}{l}\text { Cross stock risk } \\
\text { premium change }\end{array}$ & \multicolumn{2}{|c|}{$\begin{array}{l}\text { Risk appetite } \\
\text { change }\end{array}$} & \multicolumn{2}{|c|}{$\begin{array}{l}\text { Non-farm Payroll } \\
\text { growth }\end{array}$} & \multicolumn{2}{|c|}{$\begin{array}{l}\text { Stock risk (VIX) } \\
\text { change }\end{array}$} & $\begin{array}{l}\text { Adj. } \\
\mathrm{R}^{2}\end{array}$ \\
\hline \multirow{5}{*}{$\begin{array}{l}02 / 1991-03 / 1994 \\
(37)\end{array}$} & \multirow{5}{*}{$\begin{array}{l}\text { MHRC: DEM } \\
\text { SHRC: USD } \\
\text { Downturn?: No } \\
\text { Dominating market } \\
\text { given conflict: } \\
\text { Money* }\end{array}$} & \multirow{2}{*}{ Direct } & 4.88784 .1858 & 0.73011 .8968 & \multirow{2}{*}{\multicolumn{2}{|c|}{$\begin{array}{l}0.0327 \\
0.75\end{array}$}} & \multirow{2}{*}{$\begin{array}{l}-0.8314 \\
-2.72\end{array}$} & \multirow{2}{*}{$\begin{array}{l}-0.4076 \\
-1.22\end{array}$} & \multirow{2}{*}{\multicolumn{2}{|c|}{$\begin{array}{l}-0.0159 \\
-0.70\end{array}$}} & \multirow[t]{2}{*}{0.28} \\
\hline & & & $4.42 \quad 3.71$ & $0.41 \quad 2.58$ & & & & & & & \\
\hline & & \multirow{2}{*}{$\begin{array}{l}\text { Denoised } \\
(51 \%)\end{array}$} & 4.22812 .2856 & 3.12702 .9948 & \multirow{2}{*}{\multicolumn{2}{|c|}{$\begin{array}{l}0.0024 \\
0.02\end{array}$}} & -2.4661 & -0.3900 & -0.2276 & -0.0918 & \multirow{2}{*}{0.51} \\
\hline & & & $\begin{array}{ll}8.39 & 1.98\end{array}$ & $1.45 \quad 5.16$ & & & -3.64 & -0.38 & -3.08 & -0.76 & \\
\hline & & Noise & $\begin{array}{ll}5.1066 & 4.6200 \\
3.82 & 4.29\end{array}$ & $\begin{array}{ll}0.8179 & -0.0081 \\
0.61 & -0.007\end{array}$ & \multicolumn{2}{|l|}{$\begin{array}{l}0.0268 \\
0.83\end{array}$} & $\begin{array}{l}-0.6124 \\
-2.34\end{array}$ & $\begin{array}{l}-0.3630 \\
-1.03\end{array}$ & \multicolumn{2}{|l|}{$\begin{array}{l}0.0001 \\
0.007\end{array}$} & 0.22 \\
\hline \multirow{4}{*}{$\begin{array}{l}01 / 1995-01 / 1999 \\
(49)\end{array}$} & \multirow{4}{*}{$\begin{array}{l}\text { MHRC: USD } \\
\text { SHRC: USD** } \\
\text { Downturn?: No } \\
\text { Dominating market } \\
\text { given conflict: Stock }\end{array}$} & Direct & $\begin{array}{ll}4.5575 & 5.2653 \\
2.25 & 2.01\end{array}$ & $\begin{array}{ll}1.1585 & 1.6244 \\
2.11 & 7.51\end{array}$ & $\begin{array}{l}0.2339 \\
1.04\end{array}$ & $\begin{array}{l}0.0153 \\
0.31\end{array}$ & $\begin{array}{l}-0.4699 \\
-1.66\end{array}$ & $\begin{array}{l}-0.1752 \\
-0.57\end{array}$ & $\begin{array}{l}-0.0290 \\
-2.24\end{array}$ & $\begin{array}{l}-0.0337 \\
-2.14\end{array}$ & 0.20 \\
\hline & & \multirow{2}{*}{\multicolumn{2}{|c|}{$\begin{array}{lll} & & \\
\text { Denoised } & 3.1960 & 9.8903 \\
(42 \%) & 1.41 & 2.85\end{array}$}} & \multirow{2}{*}{$\begin{array}{l}3.22642 .1440 \\
6.77 \quad 4.54\end{array}$} & \multirow{2}{*}{$\begin{array}{l}0.9063 \\
4.18\end{array}$} & \multirow{3}{*}{$\begin{array}{l}0.4282 \\
1.41\end{array}$} & \multirow{2}{*}{\multicolumn{2}{|c|}{$\begin{array}{l}0.3919 \\
0.81\end{array}$}} & -0.0439 & -0.0021 & \multirow{2}{*}{0.72} \\
\hline & & & & & & & & & -1.07 & -0.03 & \\
\hline & & Noise & $\begin{array}{ll}1.7649 & 3.7114 \\
0.81 & 1.52\end{array}$ & $\begin{array}{ll}0.6711 & 1.1701 \\
1.60 & 2.10\end{array}$ & $\begin{array}{l}-0.5037 \\
-2.55\end{array}$ & & \multicolumn{2}{|l|}{$\begin{array}{l}-0.5214 \\
-2.19\end{array}$} & $\begin{array}{l}-0.0276 \\
-2.36\end{array}$ & & 0.23 \\
\hline Panel B: periods $t$ & hat are not tested and $\mathrm{r}$ & eported & & & & & & & & & \\
\hline Period & Money market HRC & $\begin{array}{l}\text { Stock ma } \\
\text { (previous }\end{array}$ & $\begin{array}{l}\text { rket HRC } \\
\text { HRC if downturn) }\end{array}$ & Stock market dow & iturn? & $\begin{array}{l}\text { Dominat } \\
\text { conflict }\end{array}$ & ng market & given & Remark & & \\
\hline 04/1994-01/1995 & $\mathrm{DEM} \rightarrow \mathrm{USD}$ & DEM (US & SD) & Yes & & stock & & & limited s & ample siz & \\
\hline
\end{tabular}

*: The dominance should is determined by comparing money market Seemingly Sharpe Ratio and HRC stock SSR, which is USD.

**: No significant difference is detected for the second half period. As analyzed in the paper, in this case, SHRC should be consistent with MHRC. 
Table II: GBP/USD

\begin{tabular}{|c|c|c|c|c|c|c|c|c|c|c|c|c|c|}
\hline \multicolumn{14}{|c|}{ Panel A: periods that are tested and reported } \\
\hline \multirow{6}{*}{$\begin{array}{l}\text { Periods } \\
\text { (\# of obs.) } \\
02 / 1991-05 / 2000 \\
\text { (excluding } \\
04 / 1994-01 / 1995, \\
10 / 1998-11 / 1998) \\
(100)\end{array}$} & \multicolumn{2}{|l|}{$\begin{array}{l}\text { Scenario identification } \\
\text { information }\end{array}$} & \multicolumn{2}{|c|}{$\begin{array}{l}\text { Interest rate } \\
\text { differential change }\end{array}$} & \multicolumn{2}{|c|}{$\begin{array}{l}\text { Cross stock risk } \\
\text { premium change }\end{array}$} & \multicolumn{2}{|c|}{$\begin{array}{l}\text { Risk appetite } \\
\text { change }\end{array}$} & \multicolumn{2}{|c|}{$\begin{array}{l}\text { Non-farm Payroll } \\
\text { growth }\end{array}$} & \multicolumn{2}{|c|}{$\begin{array}{l}\text { Stock risk (VIX) } \\
\text { change }\end{array}$} & \multirow{3}{*}{$\begin{array}{l}\text { Adj } \\
\mathrm{R}^{2} \\
0.48\end{array}$} \\
\hline & \multirow{5}{*}{$\begin{array}{l}\text { MHRC: GBP } \\
\text { SHRC: USD } \\
\text { Downturn?: No } \\
\text { Dominating market } \\
\text { given conflict: stock }\end{array}$} & \multirow{2}{*}{ Direct } & 5.4467 & 5.0353 & 0.4602 & & \multirow{2}{*}{\multicolumn{2}{|c|}{$\begin{array}{l}-0.1872 \\
-1.37\end{array}$}} & 0.3455 & \multirow{5}{*}{$\begin{array}{l}-0.0877 \\
-0.40\end{array}$} & 0.0188 & \multirow{5}{*}{$\begin{array}{l}0.0151 \\
1.21\end{array}$} & \\
\hline & & & 9.07 & 7.61 & 1.05 & & & & 2.17 & & 1.55 & & \\
\hline & & Denoised & 5.0345 & 4.9907 & 2.1251 & 2.7873 & \multirow{3}{*}{\multicolumn{2}{|c|}{$\begin{array}{l}-0.1252 \\
-1.25 \\
-0.1354 \\
-0.87\end{array}$}} & \multirow{3}{*}{$\begin{array}{l}0.2714 \\
0.76 \\
0.2291 \\
1.10 \\
\end{array}$} & & \multirow{3}{*}{$\begin{array}{l}0.0290 \\
0.91 \\
0.0170 \\
1.66 \\
\end{array}$} & & 0.70 \\
\hline & & $(52 \%)$ & 8.09 & 5.83 & 2.94 & 3.02 & & & & & & & \\
\hline & & Noise & $\begin{array}{l}4.8785 \\
7.54\end{array}$ & $\begin{array}{l}4.5452 \\
7.06\end{array}$ & $\begin{array}{l}-0.2148 \\
-0.59\end{array}$ & & & & & & & & 0.36 \\
\hline \multirow{5}{*}{$\begin{array}{l}04 / 2001-09 / 2002 \\
\text { (combined with } \\
04 / 1994-01 / 1995, \\
10 / 1998-11 / 1998) \\
(30)\end{array}$} & \multirow{5}{*}{$\begin{array}{l}\text { MHRC: GBP } \\
\text { SHRC: USD* } \\
\text { Downturn?: yes } \\
\text { Dominating market } \\
\text { given conflict: stock }\end{array}$} & \multirow{2}{*}{ Direct } & \multirow{2}{*}{\multicolumn{2}{|c|}{$\begin{array}{ll}-2.5576 & -0.8126 \\
-1.72 & -0.74\end{array}$}} & \multirow{2}{*}{\multicolumn{2}{|c|}{$\begin{array}{ll}-0.6385 & 0.1650 \\
-1.48 & 0.47\end{array}$}} & \multirow{2}{*}{$\begin{array}{l}0.4512 \\
2.32\end{array}$} & \multirow{2}{*}{$\begin{array}{l}0.2302 \\
1.81\end{array}$} & \multirow{2}{*}{\multicolumn{2}{|c|}{$\begin{array}{l}-0.5097 \\
-1.60\end{array}$}} & \multirow{2}{*}{\multicolumn{2}{|c|}{$\begin{array}{l}0.0026 \\
0.24\end{array}$}} & \multirow{2}{*}{0.23} \\
\hline & & & & & & & & & & & & & \\
\hline & & Denoised & \multirow{2}{*}{\multicolumn{2}{|c|}{$\begin{array}{ll}-3.4187 & -0.8144 \\
-2.33 & -0.81\end{array}$}} & $\mathbf{1 . 1 3 7 8}$ & 2.6396 & 0.4983 & 0.3824 & -0.0817 & 1.6817 & \multirow{2}{*}{\multicolumn{2}{|c|}{$\begin{array}{l}-0.0310 \\
-0.86\end{array}$}} & \\
\hline & & $(40 \%)$ & & & 1.92 & 5.25 & 2.55 & 2.81 & -0.11 & 3.65 & & & $0.0 /$ \\
\hline & & Noise & \multicolumn{2}{|c|}{$\begin{array}{l}-1.2546 \\
-0.93\end{array}$} & \multicolumn{2}{|l|}{$\begin{array}{l}-0.8432 \\
-1.58\end{array}$} & $\begin{array}{l}0.3025 \\
131\end{array}$ & & $\begin{array}{l}-0.6927 \\
-129\end{array}$ & & $\begin{array}{l}0.0056 \\
0.47\end{array}$ & & 0.08 \\
\hline $10 / 2002-12 / 2007$ & $\begin{array}{l}\text { MHRC: GBP } \\
\text { SHRC·GBP** }\end{array}$ & Direct & $\begin{array}{l}2.1569 \\
1.17\end{array}$ & $\begin{array}{l}2.1619 \\
1.16\end{array}$ & $\begin{array}{l}1.7197 \\
2.84\end{array}$ & $\begin{array}{l}1.7526 \\
3.96\end{array}$ & $\begin{array}{l}-0.0517 \\
-1.11\end{array}$ & & $\begin{array}{l}0.2767 \\
0.55\end{array}$ & & $\begin{array}{l}-0.0033 \\
-0.20\end{array}$ & & 0.09 \\
\hline & Downturn?: No & $\begin{array}{l}\text { Denoised } \\
(37 \%)\end{array}$ & $\begin{array}{l}2.1509 \\
2.18\end{array}$ & $\begin{array}{l}2.1352 \\
2.03\end{array}$ & $\begin{array}{l}0.1256 \\
0.11\end{array}$ & & $\begin{array}{l}0.1234 \\
0.59\end{array}$ & & $\begin{array}{l}0.7354 \\
0.62\end{array}$ & & $\begin{array}{l}-0.0367 \\
-0.70\end{array}$ & & 0.13 \\
\hline (53) & Dommating market & & 52044 & 66205 & 0.11 & 2216 & & & 0.02 & & 0000 & & \\
\hline & given contlict: stock & Noise & $\begin{array}{l}5.3944 \\
1.78 \\
\end{array}$ & $\begin{array}{l}6.6305 \\
2.69 \\
\end{array}$ & $\begin{array}{l}2.0837 \\
\mathbf{3 . 4 8} \\
\end{array}$ & $\begin{array}{l}2.2316 \\
4.25\end{array}$ & $\begin{array}{l}-0.0662 \\
-1.53\end{array}$ & & $\begin{array}{l}0.1086 \\
0.23\end{array}$ & & $\begin{array}{l}0.0026 \\
0.15\end{array}$ & & 0.25 \\
\hline anel B: periods th & at are not tested and re & ported & & & & & & & & & & & \\
\hline Period & Money market HRC & $\begin{array}{l}\text { Stock mark } \\
\text { (previous H }\end{array}$ & $\begin{array}{l}\mathrm{RC} \text { if do } \\
\mathrm{RC}\end{array}$ & wnturn) & Stock n & narket dou & turn? & $\begin{array}{l}\text { Domina } \\
\text { given ce }\end{array}$ & $\begin{array}{l}\text { g market } \\
\text { lict }\end{array}$ & & Remark & & \\
\hline $06 / 2000-03 / 2001$ & USD & USD & & & no & & & stock & & & limited s & sample siz & \\
\hline 07/2006-04/2007 & USD & GBP & & & no & & & stock & & & limited $s$ & ample siz & \\
\hline 01/2008-02/2009 & GBP & USD (GBP) & & & yes & & & stock & & & Out-of-se & ample for & cast \\
\hline 03/2009-09/2009 & GBP & $\mathrm{GBP} * * *$ & & & no & & & stock & & & Out-of-sa & ample for & cast \\
\hline
\end{tabular}

*: SHRC in downturn scenarios is the stock HRC before the downturn.

**: USD appears to be the HRC in a short period around 2005, but most time in this period, either GBP is significant HRC or no significant difference is detected, in which case, stock market HRC should be consistent with money market HRC (GBP).

***: Since our data only have 7 observations on the new uptrend, the rolling regression, which is based on historical data, might not have enough information to identify accurate stock market HRC in the new trend. Alternatively, we set stock HRC in the last uptrend as the HRC for this period. 
Table III: CAD/USD

\begin{tabular}{|c|c|c|c|c|c|c|c|c|c|c|c|c|c|}
\hline \multicolumn{14}{|c|}{ Panel A: periods that are tested and reported } \\
\hline $\begin{array}{l}\text { Period } \\
\text { (\# of obs.) }\end{array}$ & $\begin{array}{l}\text { Scenario identification } \\
\text { information }\end{array}$ & & \multicolumn{2}{|c|}{ differential change } & \multicolumn{2}{|c|}{$\begin{array}{l}\text { Cross stock risk } \\
\text { premium change }\end{array}$} & \multicolumn{2}{|c|}{$\begin{array}{l}\text { Risk appetite } \\
\text { change }\end{array}$} & \multicolumn{2}{|c|}{$\begin{array}{l}\text { Non-farm Payroll } \\
\text { growth }\end{array}$} & \multicolumn{2}{|c|}{$\begin{array}{l}\text { Stock risk (VIX) } \\
\text { change }\end{array}$} & \multirow{2}{*}{$\begin{array}{l}\text { Adj. } \\
\mathrm{R}^{2} \\
0.21\end{array}$} \\
\hline \multirow{3}{*}{$\begin{array}{l}02 / 1991-02 / 1996 \\
\text { (excluding 04/1994- } \\
01 / 1995) \\
(50)\end{array}$} & \multirow{3}{*}{$\begin{array}{l}\text { MHRC: CAD } \\
\text { SHRC: USD } \\
\text { Downturn?: No } \\
\text { Dominating market given } \\
\text { conflict: stock }\end{array}$} & Direct & $\begin{array}{l}-1.0451 \\
-3.18\end{array}$ & $\begin{array}{l}-1.0726^{*} \\
-4.25\end{array}$ & \multicolumn{2}{|c|}{$\begin{array}{l}0.0313 \\
0.06\end{array}$} & \multicolumn{2}{|c|}{$\begin{array}{l}0.0212 \\
1.23\end{array}$} & \multicolumn{2}{|c|}{$\begin{array}{l}0.1123 \\
0.62\end{array}$} & \multicolumn{2}{|c|}{$\begin{array}{l}0.0121 \\
1.52\end{array}$} & \\
\hline & & $\begin{array}{l}\text { Denoised } \\
(59 \%)\end{array}$ & $\begin{array}{l}-0.6871 \\
-1.84\end{array}$ & $\begin{array}{l}-0.6144 \\
-0.91\end{array}$ & $\begin{array}{l}0.2015 \\
0.37\end{array}$ & & $\begin{array}{l}0.2844 \\
7.00\end{array}$ & $\begin{array}{l}0.1887 \\
3.49\end{array}$ & \multicolumn{2}{|l|}{$\begin{array}{l}-0.1856 \\
-0.62\end{array}$} & \multicolumn{2}{|l|}{$\begin{array}{l}0.0280 \\
1.36\end{array}$} & 0.66 \\
\hline & & Noise & $\begin{array}{l}-0.6713 \\
-2.03\end{array}$ & $\begin{array}{l}-0.7061 \\
-2.61\end{array}$ & $\begin{array}{l}0.3483 \\
0.72 \\
\end{array}$ & $\begin{array}{l}0.4885 \\
1.12 \\
\end{array}$ & $\begin{array}{l}0.0054 \\
0.36 \\
\end{array}$ & & $\begin{array}{l}0.2012 \\
1.24\end{array}$ & & $\begin{array}{l}-0.0110 \\
-1.34\end{array}$ & & 0.10 \\
\hline \multirow{2}{*}{$\begin{array}{l}03 / 1996-06 / 1999 \\
\text { (excluding 10/1998- } \\
11 / 1998) \\
(38)\end{array}$} & \multirow{2}{*}{$\begin{array}{l}\text { MHRC: USD } \\
\text { SHRC: USD } \\
\text { Downturn?: No } \\
\text { Dominating market given } \\
\text { conflict: stock }\end{array}$} & \multirow{2}{*}{$\begin{array}{l}\text { Direct } \\
\text { Denoised } \\
(48 \%)\end{array}$} & \multicolumn{2}{|l|}{$\begin{array}{l}-1.0421 \\
-1.42\end{array}$} & \multicolumn{2}{|l|}{$\begin{array}{l}0.0906 \\
0.24\end{array}$} & $\begin{array}{l}0.3657 \\
2.59\end{array}$ & $\begin{array}{l}0.3332 \\
3.24\end{array}$ & $\begin{array}{l}-0.0897 \\
-0.35\end{array}$ & & \multirow{2}{*}{\multicolumn{2}{|c|}{$\begin{array}{l}-0.0043 \\
-0.31 \\
0.0092 \\
0.62 \\
-0.0032 \\
-0.27 \\
\end{array}$}} & 0.10 \\
\hline & & & $\begin{array}{l}-1.8057 \\
-7.14 \\
-0.2183 \\
-0.15 \\
\end{array}$ & $\begin{array}{l}-2.1217 * \\
-3.20\end{array}$ & $\begin{array}{l}-1.0321 \\
-0.44 \\
0.4090 \\
1.01 \\
\end{array}$ & & $\begin{array}{l}\mathbf{0 . 2 4 8 2} \\
\mathbf{3 . 1 0} \\
0.2481 \\
1.44 \\
\end{array}$ & $\begin{array}{l}0.3725 \\
3.66\end{array}$ & $\begin{array}{l}0.4612 \\
1.93 \\
-0.1127 \\
-0.48 \\
\end{array}$ & $\begin{array}{l}0.7146 \\
1.30\end{array}$ & & & 0.03 \\
\hline \multirow{3}{*}{$\begin{array}{l}07 / 1999-03 / 2001 \\
\text { (combined with } \\
01 / 2005-12 / 2007 \text { ) } \\
(57)\end{array}$} & \multirow{3}{*}{$\begin{array}{l}\text { MHRC: USD } \\
\text { SHRC: CAD } \\
\text { Downturn?: No } \\
\text { Dominating market given } \\
\text { conflict: stock }\end{array}$} & Direct & $\begin{array}{l}3.3413 \\
2.30\end{array}$ & $\begin{array}{l}2.0294 \\
1.38\end{array}$ & $\begin{array}{l}0.8799 \\
3.34\end{array}$ & $\begin{array}{l}0.8617 \\
4.05\end{array}$ & \multicolumn{2}{|l|}{$\begin{array}{l}-0.0253 \\
-0.18\end{array}$} & $\begin{array}{l}0.7029 \\
2.18\end{array}$ & $\begin{array}{l}0.1909 \\
0.69\end{array}$ & \multicolumn{2}{|l|}{$\begin{array}{l}-0.0071 \\
-0.48\end{array}$} & 0.18 \\
\hline & & $\begin{array}{l}\text { Denoised } \\
(52 \%)\end{array}$ & $\begin{array}{l}2.8962 \\
1.99\end{array}$ & $\begin{array}{l}0.0314 \\
0.01\end{array}$ & $\begin{array}{l}1.7408 \\
3.68\end{array}$ & $\begin{array}{l}0.4945 \\
1.86\end{array}$ & $\begin{array}{l}-0.1003 \\
-1.17\end{array}$ & & $\begin{array}{l}1.8213 \\
3.66\end{array}$ & $\begin{array}{l}1.4074 \\
3.29\end{array}$ & $\begin{array}{l}0.1757 \\
7.13\end{array}$ & $\begin{array}{l}0.1267 \\
2.18\end{array}$ & 0.70 \\
\hline & & Noise & $\begin{array}{l}3.8350 \\
3.56\end{array}$ & $\begin{array}{l}4.3544 \\
4.23\end{array}$ & $\begin{array}{l}0.5653 \\
1.59\end{array}$ & $\begin{array}{l}0.9280 \\
4.34\end{array}$ & $\begin{array}{l}-0.1264 \\
-0.64\end{array}$ & & $\begin{array}{l}0.3677 \\
1.82\end{array}$ & $\begin{array}{l}-0.0908 \\
0.37\end{array}$ & $\begin{array}{l}--0.0196 \\
-1.32\end{array}$ & & 0.28 \\
\hline & MHRC: CAD & Direct & $\begin{array}{l}3.3027 \\
2.86\end{array}$ & $\begin{array}{l}3.4080 \\
3.66\end{array}$ & $\begin{array}{l}-0.0372 \\
-0.18\end{array}$ & & $\begin{array}{l}-0.1109 \\
-0.72\end{array}$ & & $\begin{array}{l}0.6831 \\
7.84\end{array}$ & $\begin{array}{l}0.6954 \\
3.97\end{array}$ & $\begin{array}{l}-0.0162 \\
-0.97\end{array}$ & & 0.44 \\
\hline $\begin{array}{l}04 / 2001-09 / 2002 \\
(18)\end{array}$ & $\begin{array}{l}\text { SHRC: CAD } \\
\text { Downturn?: Yes } \\
\text { Dominating market given }\end{array}$ & $\begin{array}{l}\text { Denoised } \\
(50 \%)\end{array}$ & $\begin{array}{l}3.3794 \\
3.33\end{array}$ & $\begin{array}{l}1.8591 \\
1.74\end{array}$ & $\begin{array}{l}-0.3702 \\
-0.68\end{array}$ & & $\begin{array}{l}-0.2552 \\
-6.42\end{array}$ & $\begin{array}{l}0.0003 \\
0.004\end{array}$ & $\begin{array}{l}1.0184 \\
2.63\end{array}$ & $\begin{array}{l}1.4037 \\
2.82\end{array}$ & $\begin{array}{l}-0.0190 \\
-0.93\end{array}$ & & 0.79 \\
\hline & conflict: stock & Noise & $\begin{array}{l}1.7368 \\
1.54\end{array}$ & & $\begin{array}{l}0.4961 \\
2.51\end{array}$ & $\begin{array}{l}0.5605 \\
2.65\end{array}$ & $\begin{array}{l}0.2680 \\
2.35\end{array}$ & $\begin{array}{l}0.2212 \\
1.97\end{array}$ & $\begin{array}{l}0.3336 \\
1.85\end{array}$ & $\begin{array}{l}0.5916 \\
4.18\end{array}$ & $\begin{array}{l}-0.0082 \\
-0.51\end{array}$ & & 0.33 \\
\hline & MHRC: CAD & Direct & $\begin{array}{l}3.3899 \\
2.37\end{array}$ & $\begin{array}{l}3.6995 \\
2.61\end{array}$ & $\begin{array}{l}2.9231 \\
3.65\end{array}$ & $\begin{array}{l}1.7942 \\
2.80\end{array}$ & $\begin{array}{l}-0.0638 \\
-1.30\end{array}$ & $\begin{array}{l}-0.0214 \\
-0.55\end{array}$ & $\begin{array}{l}0.9806 \\
2.14\end{array}$ & $\begin{array}{l}0.2463 \\
0.55\end{array}$ & $\begin{array}{l}0.0358 \\
1.16\end{array}$ & & 0.26 \\
\hline $\begin{array}{l}10 / 2002-12 / 2004 \\
(27)\end{array}$ & $\begin{array}{l}\text { SHRC: CAD** } \\
\text { Downturn?: No } \\
\text { Dominating market given }\end{array}$ & $\begin{array}{l}\text { Denoised } \\
(52 \%)\end{array}$ & $\begin{array}{l}3.7829 \\
4.01\end{array}$ & $\begin{array}{l}0.9152 \\
0.43\end{array}$ & $\begin{array}{l}2.4644 \\
2.22\end{array}$ & $\begin{array}{l}3.6822 \\
3.68\end{array}$ & $\begin{array}{l}0.3116 \\
2.57\end{array}$ & $\begin{array}{l}0.2639 \\
1.61\end{array}$ & $\begin{array}{l}-0.1856 \\
-0.21\end{array}$ & & $\begin{array}{l}-0.1404 \\
-2.59\end{array}$ & $\begin{array}{l}-0.2446 \\
-6.73\end{array}$ & 0.72 \\
\hline & conflict: stock & Noise & $\begin{array}{l}5.3939 \\
2.64\end{array}$ & $\begin{array}{l}5.7568 \\
2.01 \\
\end{array}$ & $\begin{array}{l}-0.3833 \\
-0.85 \\
\end{array}$ & & $\begin{array}{l}-0.0883 \\
-3.01\end{array}$ & $\begin{array}{l}-0.0470 \\
-1.60\end{array}$ & $\begin{array}{l}0.8475 \\
2.88\end{array}$ & $\begin{array}{l}0.2301 \\
0.59\end{array}$ & $\begin{array}{l}0.0536 \\
3.48 \\
\end{array}$ & $\begin{array}{l}-0.0022 \\
-0.08\end{array}$ & 0.49 \\
\hline Panel B: periods that & are not tested and reported & & & & & & & & & & & & \\
\hline Period & Money market HRC & $\begin{array}{l}\begin{array}{l}\text { Stock mar } \\
\text { (previous }\end{array} \\
\end{array}$ & $\begin{array}{l}\text { HRC } \\
\mathrm{C} \text { if down }\end{array}$ & urn) & Stock m & arket dow & & $\begin{array}{l}\text { Domine } \\
\text { given c }\end{array}$ & $\begin{array}{l}\text { g market } \\
\text { lict }\end{array}$ & & Remark & & \\
\hline 04/1994-01/1995 & CAD & CAD (US & & & yes & & & stock & & & limited $s$ & sample siz & \\
\hline 10/1998-11/1998 & USD & USD (US & & & yes & & & stock & & & limited s & sample siz & \\
\hline 01/2008-02/2009 & CAD & No signifi & $t$ differenc & (CAD) & yes & & & stock & & & Out-of-s & ample for & \\
\hline 03/2009-09/2009 & CAD & CAD*** & & & no & & & stock & & & Out-of-s & ample for & \\
\hline
\end{tabular}

*: Although these results, which are significant and robust, seem against the model, they are reconciled with the dominating stock reallocation and not considered as opposing evidence.

**: No significant difference is detected most time for this period. As analyzed in the paper, in this case, SHRC should be consistent with MHRC.

***: As explained in the paper, we set stock HRC in the last uptrend as the HRC for this period. 
Table IV: EUR/USD

\begin{tabular}{|c|c|c|c|c|c|c|c|c|c|c|c|c|c|}
\hline \multicolumn{14}{|c|}{ Panel A: periods that are tested and reported } \\
\hline \multirow{4}{*}{$\begin{array}{l}\begin{array}{l}\text { Period } \\
\text { (\# of obs.) }\end{array} \\
\\
01 / 1999-03 / 2001 \\
(27)\end{array}$} & \multicolumn{2}{|l|}{$\begin{array}{l}\text { Scenario identification } \\
\text { information }\end{array}$} & \multicolumn{2}{|c|}{$\begin{array}{l}\text { Interest rate } \\
\text { differential change }\end{array}$} & \multicolumn{2}{|c|}{$\begin{array}{l}\text { Cross stock risk } \\
\text { premium change }\end{array}$} & \multicolumn{2}{|c|}{$\begin{array}{l}\text { Risk appetite } \\
\text { change }\end{array}$} & \multicolumn{2}{|c|}{$\begin{array}{l}\text { Non-farm Payroll } \\
\text { growth }\end{array}$} & \multicolumn{2}{|c|}{$\begin{array}{l}\text { Stock risk (VIX) } \\
\text { change }\end{array}$} & \multirow{2}{*}{$\begin{array}{l}\text { Adj } \\
\mathrm{R}^{2} \\
0.15\end{array}$} \\
\hline & \multirow{3}{*}{$\begin{array}{l}\text { MHRC: USD } \\
\text { SHRC: EUR } \\
\text { Downturn?: No } \\
\text { Dominating market } \\
\text { given conflict: stock }\end{array}$} & \multirow{2}{*}{$\begin{array}{l}\text { Direct } \\
\text { Denoised } \\
(49 \%)\end{array}$} & \multicolumn{2}{|l|}{$\begin{array}{l}-2.2343 \\
-0.81\end{array}$} & \multicolumn{2}{|l|}{$\begin{array}{l}-0.2452 \\
-0.25\end{array}$} & \multicolumn{2}{|l|}{$\begin{array}{l}0.0466 \\
0.10\end{array}$} & \multicolumn{2}{|c|}{$\begin{array}{ll}-1.9566 & -1.6108 \\
-3.34 & -3.59\end{array}$} & \multicolumn{2}{|l|}{$\begin{array}{l}0.0374 \\
1.26\end{array}$} & \\
\hline & & & $\begin{array}{l}-3.4004 \\
-2.22\end{array}$ & $\begin{array}{l}-1.0906 \\
-1.04\end{array}$ & \multicolumn{2}{|l|}{$\begin{array}{l}-1.2675 \\
-1.69\end{array}$} & \multicolumn{2}{|l|}{$\begin{array}{l}-0.0013 \\
-0.004\end{array}$} & \multicolumn{2}{|c|}{$\begin{array}{ll}-3.7451 & -3.6294 \\
-9.96 & -10.77\end{array}$} & \multicolumn{2}{|l|}{$\begin{array}{l}0.0580 \\
1.00\end{array}$} & 0.76 \\
\hline & & Noise & \multicolumn{2}{|l|}{$\begin{array}{l}-1.1963 \\
-0.28 \\
\end{array}$} & $\begin{array}{l}1.2470 \\
1.37 \\
\end{array}$ & $\begin{array}{l}1.6230 \\
4.48 \\
\end{array}$ & \multicolumn{2}{|l|}{$\begin{array}{l}1.2470 \\
1.37 \\
\end{array}$} & \multicolumn{2}{|l|}{$\begin{array}{l}-1.1503 \\
-1.51 \\
\end{array}$} & \multicolumn{2}{|l|}{$\begin{array}{l}0.0230 \\
0.71 \\
\end{array}$} & 0.11 \\
\hline \multirow{3}{*}{$\begin{array}{l}04 / 2001-09 / 2002 \\
(18)\end{array}$} & \multirow{3}{*}{$\begin{array}{l}\text { MHRC: EUR } \\
\text { SHRC: USD* } \\
\text { Downturn?: Yes } \\
\text { Dominating market } \\
\text { given conflict: stock }\end{array}$} & Direct & \multicolumn{2}{|l|}{$\begin{array}{l}-1.0813 \\
-0.45\end{array}$} & $\begin{array}{l}0.7606 \\
1.91\end{array}$ & $\begin{array}{l}0.7447 \\
1.95\end{array}$ & \multicolumn{2}{|l|}{$\begin{array}{l}-0.0865 \\
-1.21\end{array}$} & \multicolumn{2}{|l|}{$\begin{array}{l}0.4168 \\
1.00\end{array}$} & $\begin{array}{l}-0.0021 \\
-0.06\end{array}$ & & 0.16 \\
\hline & & $\begin{array}{l}\text { Denoised } \\
(56 \%)\end{array}$ & $\begin{array}{l}-2.6363 \\
-0.81\end{array}$ & & $\begin{array}{l}6.4259 \\
3.40\end{array}$ & $\begin{array}{l}3.4632 \\
5.12\end{array}$ & $\begin{array}{l}0.1432 \\
0.26\end{array}$ & & $\begin{array}{l}0.7263 \\
0.48\end{array}$ & & $\begin{array}{l}0.0900 \\
0.70\end{array}$ & $\begin{array}{l}-0.1225 \\
-3.56\end{array}$ & 0.49 \\
\hline & & Noise & $\begin{array}{l}0.7880 \\
0.13 \\
\end{array}$ & & $\begin{array}{l}0.1083 \\
0.12 \\
\end{array}$ & & $\begin{array}{l}-0.0405 \\
-0.43 \\
\end{array}$ & & $\begin{array}{l}0.6251 \\
0.73 \\
\end{array}$ & & $\begin{array}{l}0.0040 \\
0.09 \\
\end{array}$ & & 0.04 \\
\hline & $\begin{array}{l}\text { MHRC: EUR } \\
\text { SHRC. FUR** }\end{array}$ & Direct & $\begin{array}{l}-3.9084 \\
-1.24\end{array}$ & & $\begin{array}{l}1.4632 \\
1.94\end{array}$ & $\begin{array}{l}1.5950 \\
2.45\end{array}$ & $\begin{array}{l}0.5641 \\
1.81\end{array}$ & $\begin{array}{l}0.6060 \\
2.46\end{array}$ & $\begin{array}{l}0.4296 \\
0.61\end{array}$ & & $\begin{array}{l}0.0244 \\
0.95\end{array}$ & & 0.14 \\
\hline $\begin{array}{l}10 / 2002-12 / 2004 \\
(27)\end{array}$ & $\begin{array}{l}\text { SHRC: EUR* } \\
\text { Downturn?: No } \\
\text { Dominating market }\end{array}$ & $\begin{array}{l}\text { Denoised } \\
(52 \%)\end{array}$ & $\begin{array}{l}-2.9431 \\
-1.21\end{array}$ & & $\begin{array}{l}-0.5041 \\
-0.55\end{array}$ & $\begin{array}{l}2.3014 \\
2.85\end{array}$ & $\begin{array}{l}-0.0565 \\
-0.28\end{array}$ & $\begin{array}{l}0.2400 \\
0.61\end{array}$ & $\begin{array}{l}-2.4062 \\
-2.77\end{array}$ & $\begin{array}{l}-1.4111 \\
-1.09\end{array}$ & $\begin{array}{l}-0.2256 \\
-2.55\end{array}$ & $\begin{array}{l}-0.2215 \\
-3.78\end{array}$ & 0.47 \\
\hline & given conflict: stock & Noise & $\begin{array}{l}-1.7503 \\
-0.38 \\
\end{array}$ & & $\begin{array}{l}1.1283 \\
1.41 \\
\end{array}$ & $\begin{array}{l}1.4208 \\
1.80 \\
\end{array}$ & $\begin{array}{l}1.0712 \\
4.92 \\
\end{array}$ & $\begin{array}{l}0.9362 \\
4.43 \\
\end{array}$ & $\begin{array}{l}0.8306 \\
1.52 \\
\end{array}$ & $\begin{array}{l}0.2206 \\
0.37 \\
\end{array}$ & $\begin{array}{l}0.0235 \\
1.03 \\
\end{array}$ & & 0.27 \\
\hline & MHRC: USD & Direct & $\begin{array}{l}3.2037 \\
2.29\end{array}$ & $\begin{array}{l}3.0150 \\
2.16\end{array}$ & $\begin{array}{l}0.3588 \\
0.58\end{array}$ & & $\begin{array}{l}0.0054 \\
0.07\end{array}$ & & $\begin{array}{l}0.0923 \\
0.17\end{array}$ & & $\begin{array}{l}-0.0090 \\
-0.74\end{array}$ & & 0.08 \\
\hline $\begin{array}{l}01 / 2005-12 / 2007 \\
(36)\end{array}$ & $\begin{array}{l}\text { SHRC: EUR } \\
\text { Downturn?: No } \\
\text { Dominating market }\end{array}$ & $\begin{array}{l}\text { Denoised } \\
(44 \%)\end{array}$ & $\begin{array}{l}\mathbf{5 . 7 1 7 9} \\
\mathbf{5 . 9 5}\end{array}$ & $\begin{array}{l}3.9007 \\
3.35\end{array}$ & $\begin{array}{l}1.8429 \\
1.32\end{array}$ & & $\begin{array}{l}-0.2911 \\
-1.64\end{array}$ & $\begin{array}{l}0.1990 \\
1.68\end{array}$ & $\begin{array}{l}2.5067 \\
2.94\end{array}$ & $\begin{array}{l}0.0610 \\
0.05\end{array}$ & $\begin{array}{l}0.0844 \\
1.88\end{array}$ & $\begin{array}{l}-0.0106 \\
-0.78\end{array}$ & 0.66 \\
\hline & given conflict: stock & Noise & $\begin{array}{l}0.7784 \\
0.42 \\
\end{array}$ & & & $\begin{array}{l}1.0096 \\
1.32\end{array}$ & $\begin{array}{l}-0.0228 \\
-0.31\end{array}$ & & $\begin{array}{l}-0.2554 \\
-0.49\end{array}$ & & $\begin{array}{l}-0.0166 \\
-1.71\end{array}$ & & 0.00 \\
\hline anel B: periods & at are not tested and rep & & & & & & & & & & & & \\
\hline Period & Money market HRC & $\begin{array}{l}\text { Stock ma1 } \\
\text { (previous }\end{array}$ & $\begin{array}{l}\text { rket HRC } \\
\text { HRC if }\end{array}$ & downturn) & Stock m & narket dow & urn? & $\begin{array}{l}\text { Domin } \\
\text { given o }\end{array}$ & $\begin{array}{l}\text { ing marke } \\
\text { nflict }\end{array}$ & & Remark & & \\
\hline $01 / 2008-02 / 2009$ & EUR & EUR (EU & JR) & & yes & & & stock & & & Out-of-s & sample for & cast \\
\hline 03/2009-09/2009 & EUR & $\mathrm{EUR}^{* * *}$ & & & no & & & stock & & & Out-of-s & sample for & cast \\
\hline
\end{tabular}

*: Before stock market bubble started bursting in 2001, the USD appreciated relative to the EUR, which must mean that funds from the Europe flew into the dollar assets. This implies that the USD is actually the stock market HRC before the downturn, although our rolling regression suggests the opposite.

**: No significant difference is detected for the second half period. As analyzed in the paper, in this case, SHRC should be consistent with MHRC.

***: We set stock market HRC in the most recent uptrend as the HRC for this period. 
Table V: JPY/USD

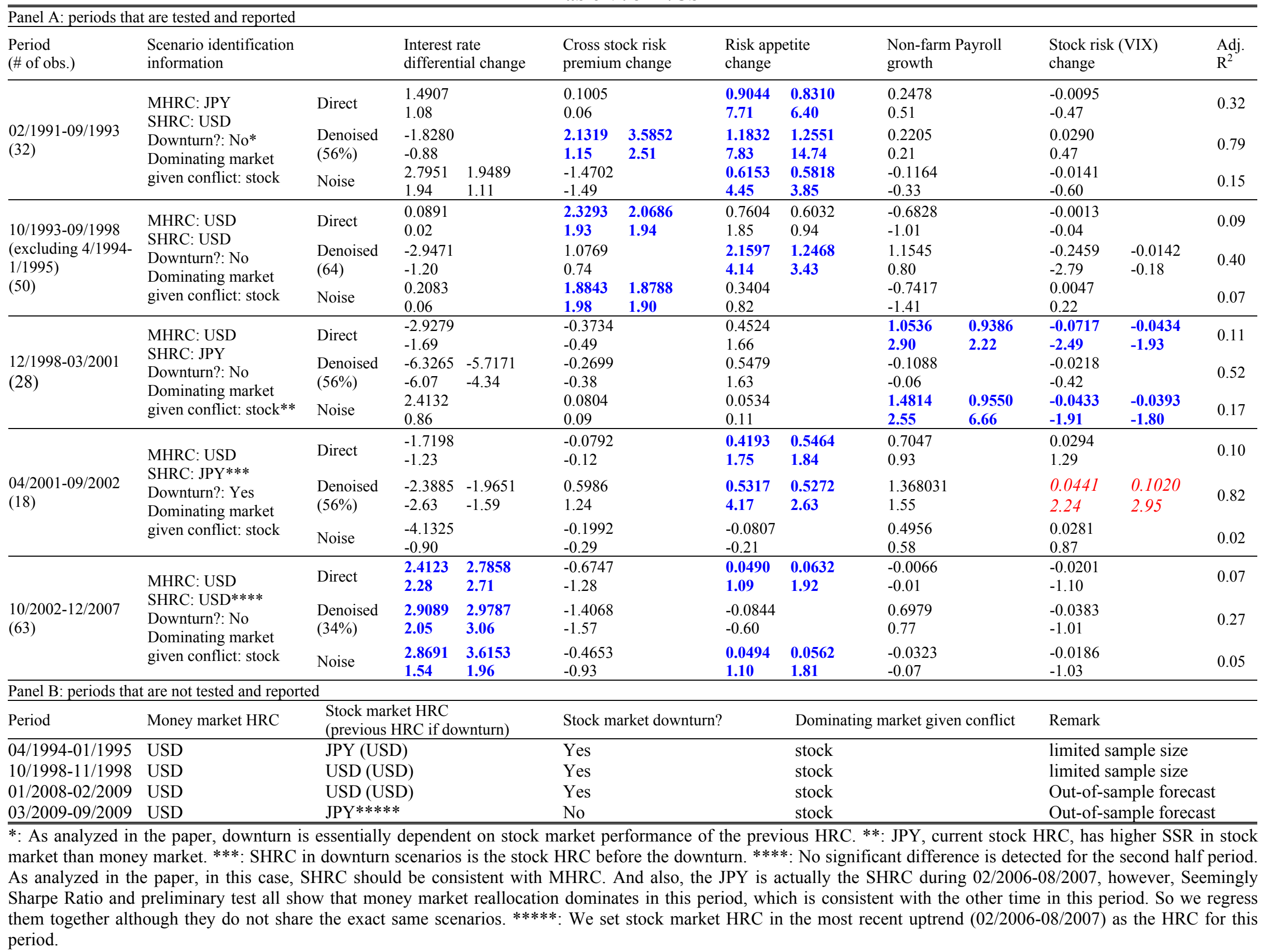




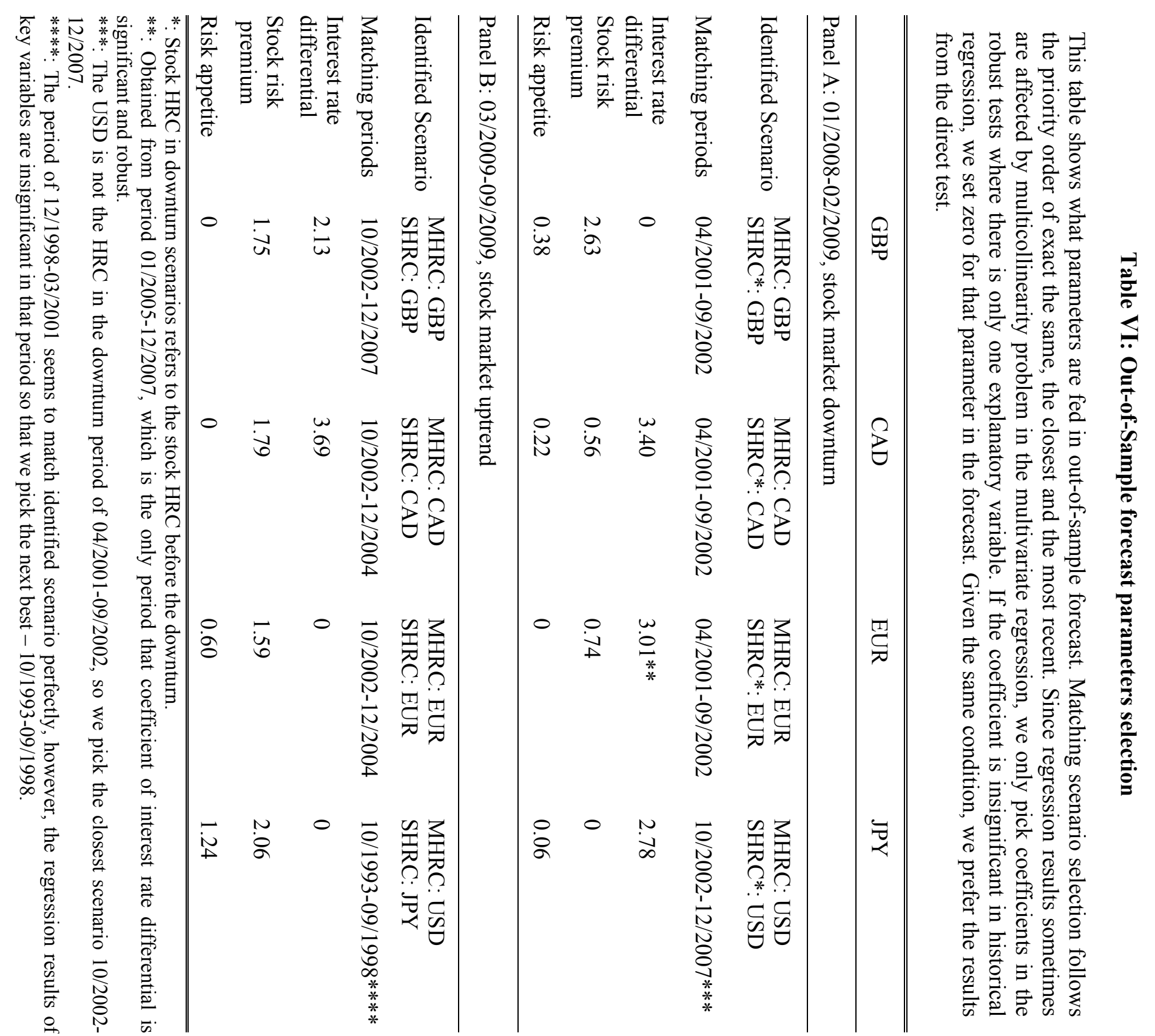




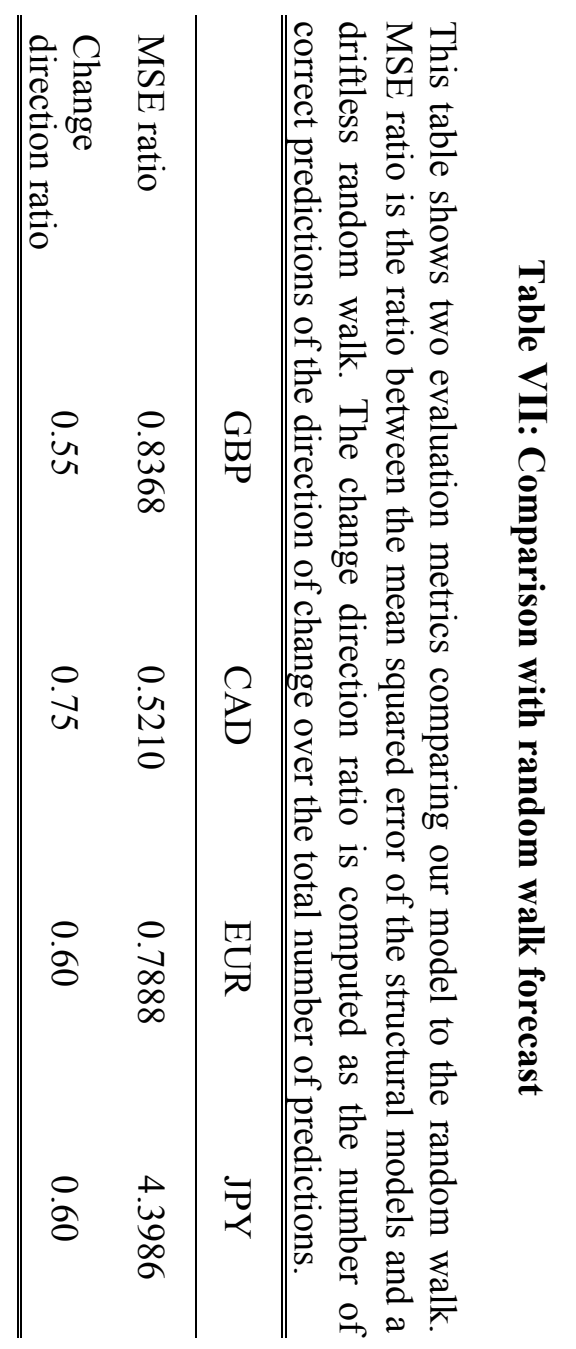






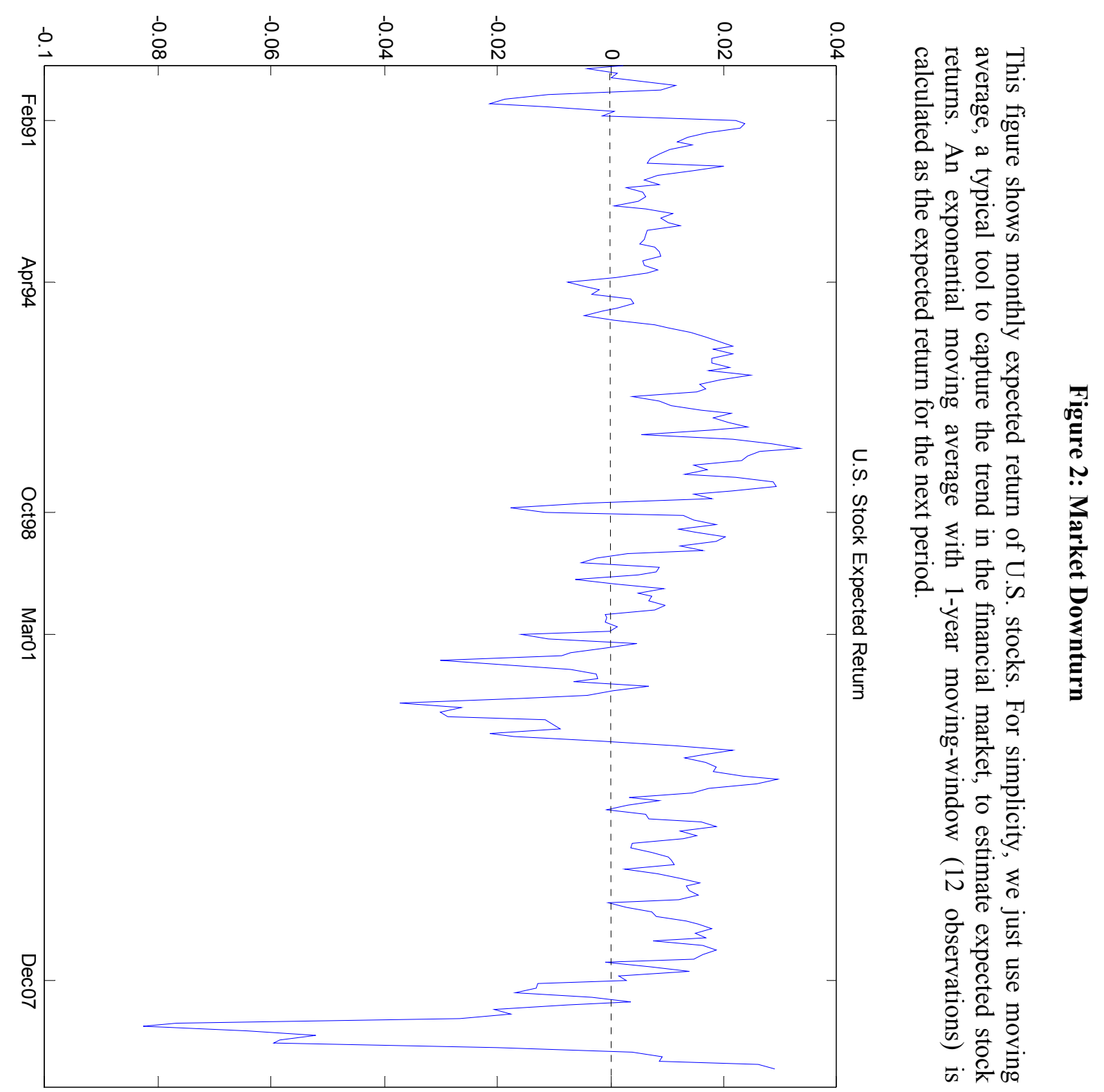




\section{Figure 3: DEM/USD}

This figure shows scenario identification information and relationship between exchange rate dynamics and major explanatory variables. Foreign currency is stock market HRC if the coefficient is higher than one in the first sub-figure. Foreign currency is money market HRC if the interest rate differential is positive in the second subfigure. Dominating market can be seen from the last subfigure. Blue solid line and red dash line represent raw and filtered data respectively in subfigure 2 and 3. Subfigure 4 displays the dynamics of cross stock risk premium. The notes also apply to the similar figures of the other currencies.

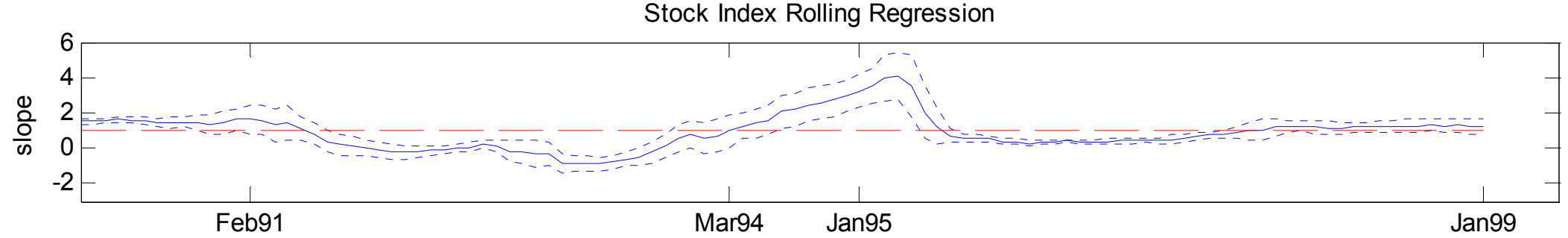

Interest Rate Differential (DEM-USD)

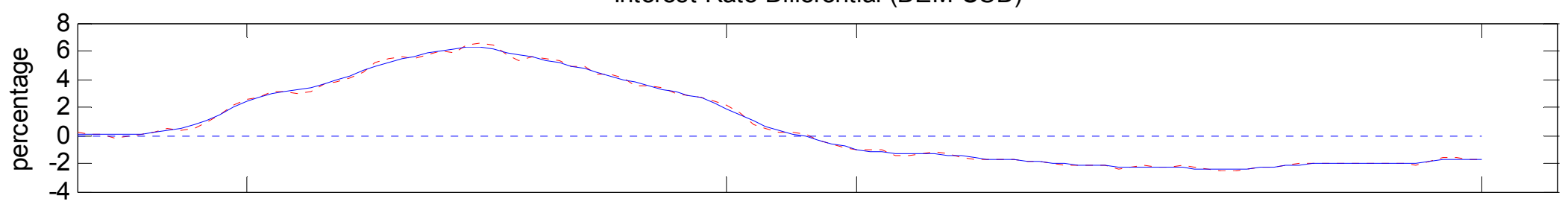

Exchange Rate (DEM/USD)
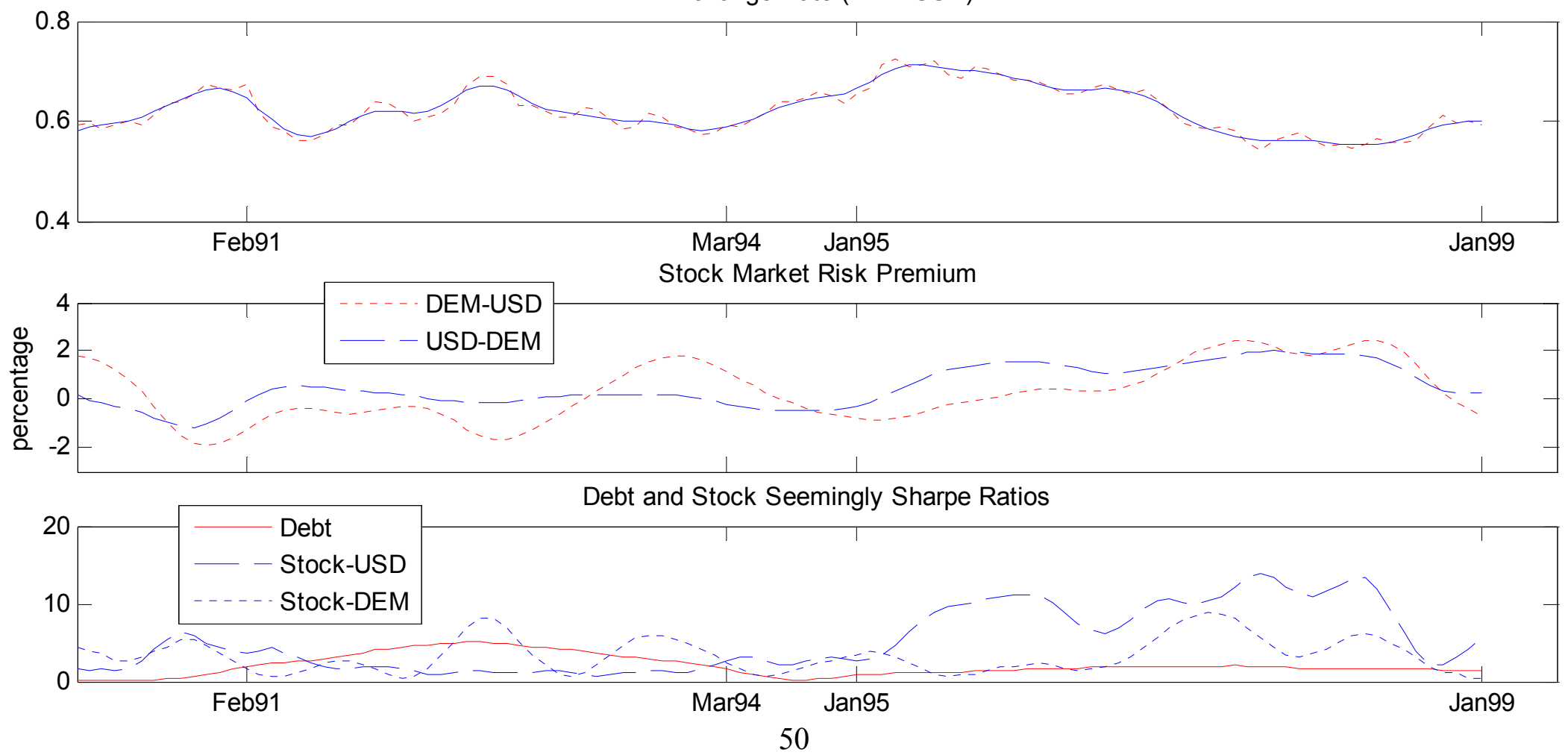
Figure 4: GBP/USD
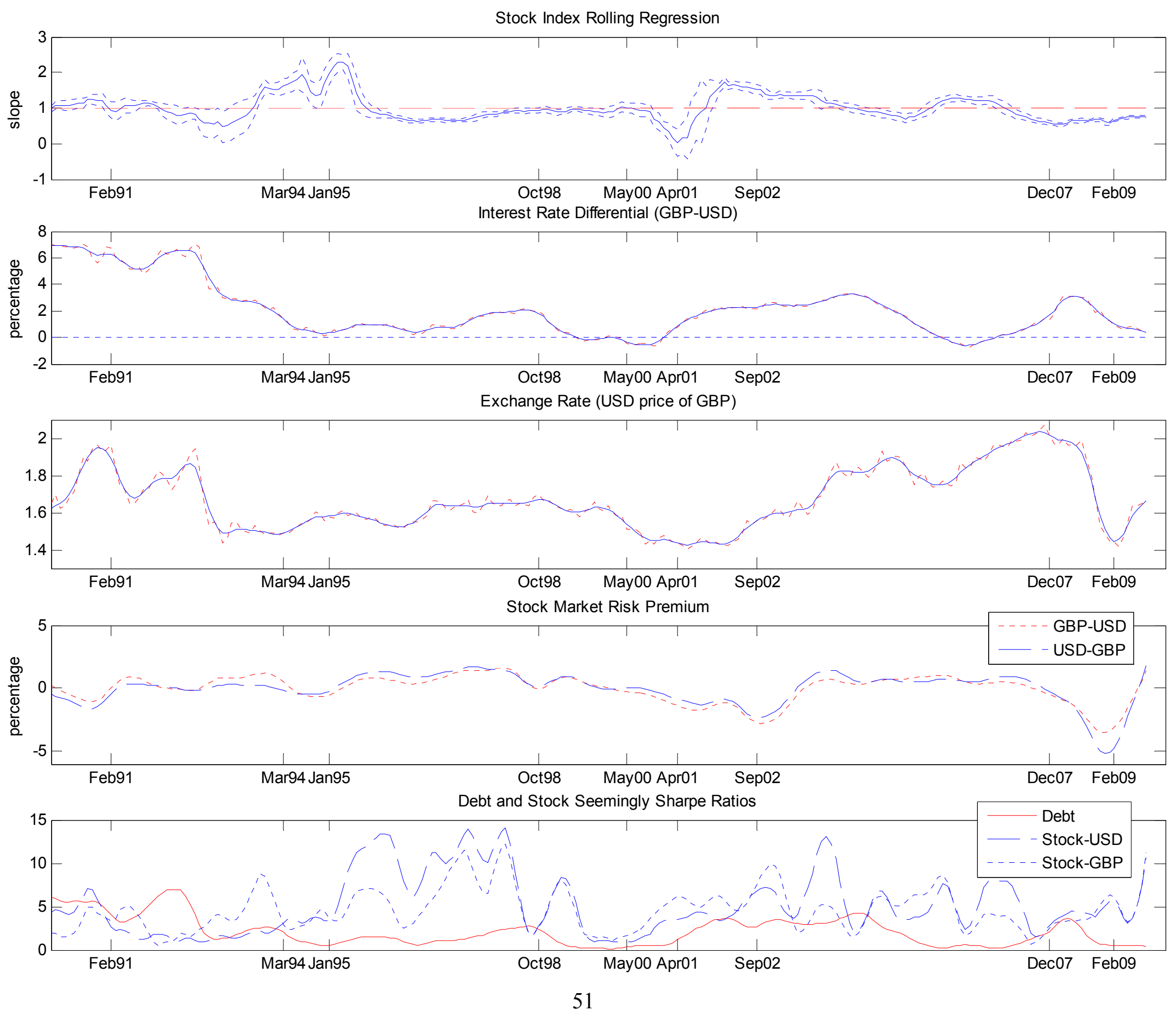


\section{Figure 5: CAD/USD}

Stock Index Rolling Regression

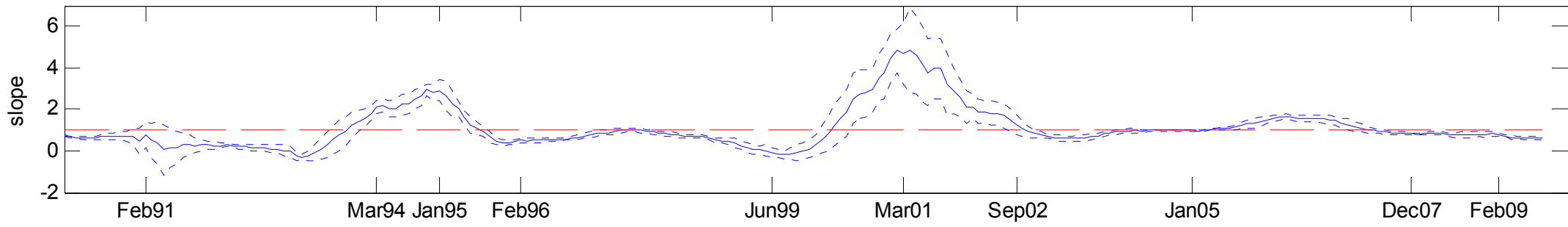

Interest Rate Differential (CAD-USD)
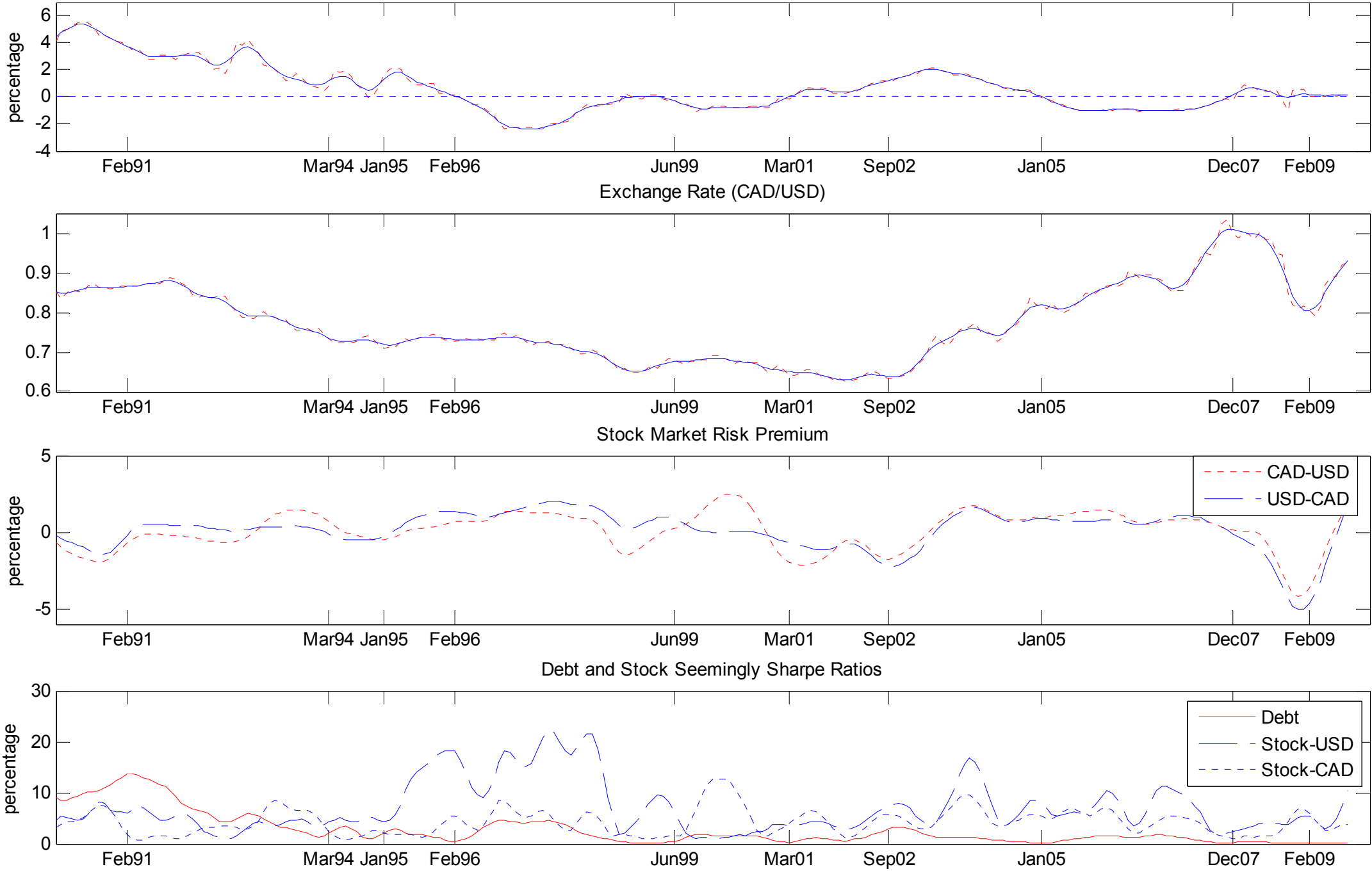


\section{Figure 6: EUR/USD}

Stock Index Rolling Regression
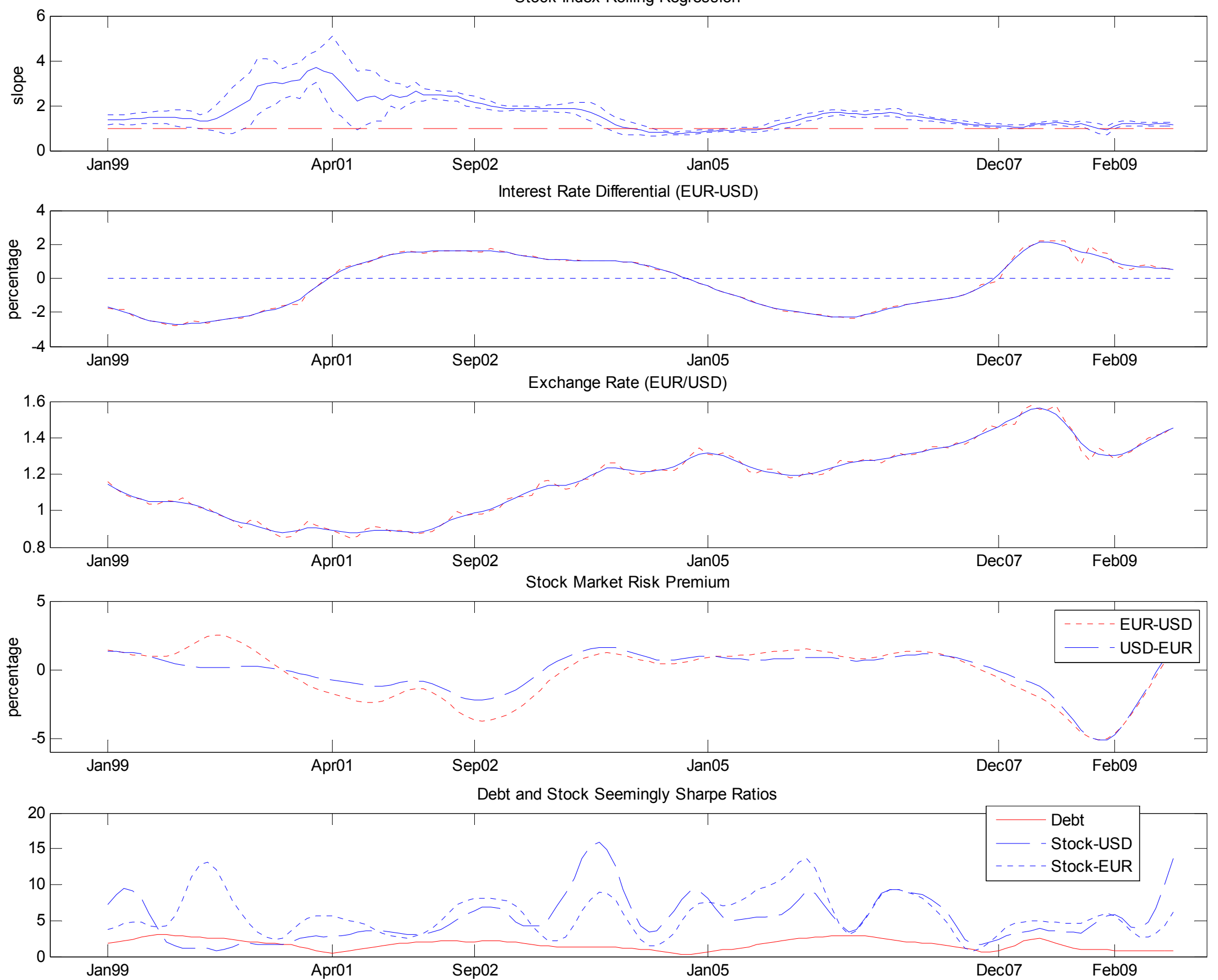
Figure 7: JPY/USD
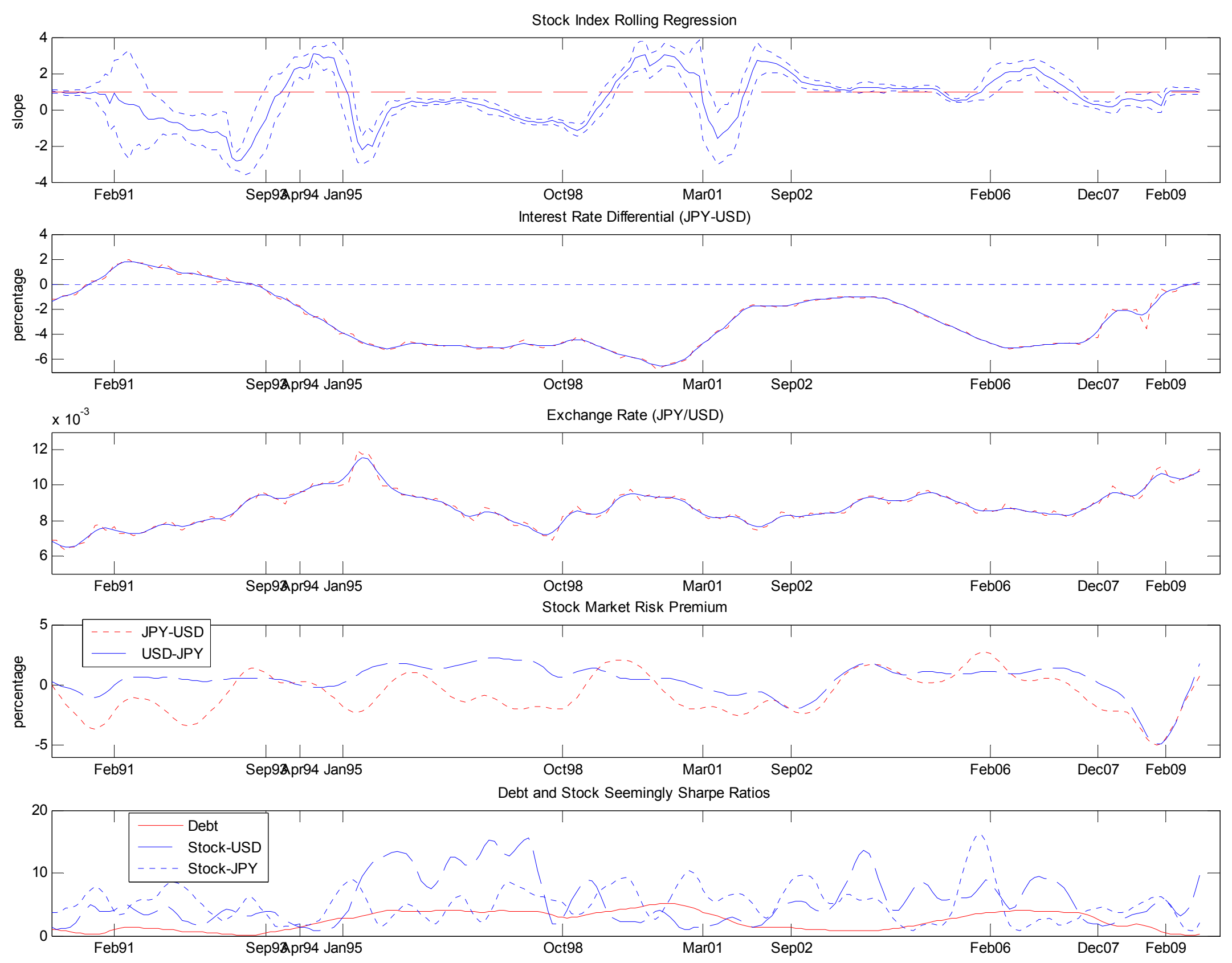


\section{Figure 8: Out-of-sample forecast}

These figures display out-of-sample forecast for various exchange rates. Forecasted exchange rate at the current period is calculated based on model-implied exchange rate return and forecasted rate in the previous period. Thus, this forecast does not use any information from the FX market in the forecast period. In each subfigure, blue solid

line represents actual exchange rate, and red dash line represents model-forecasted one.
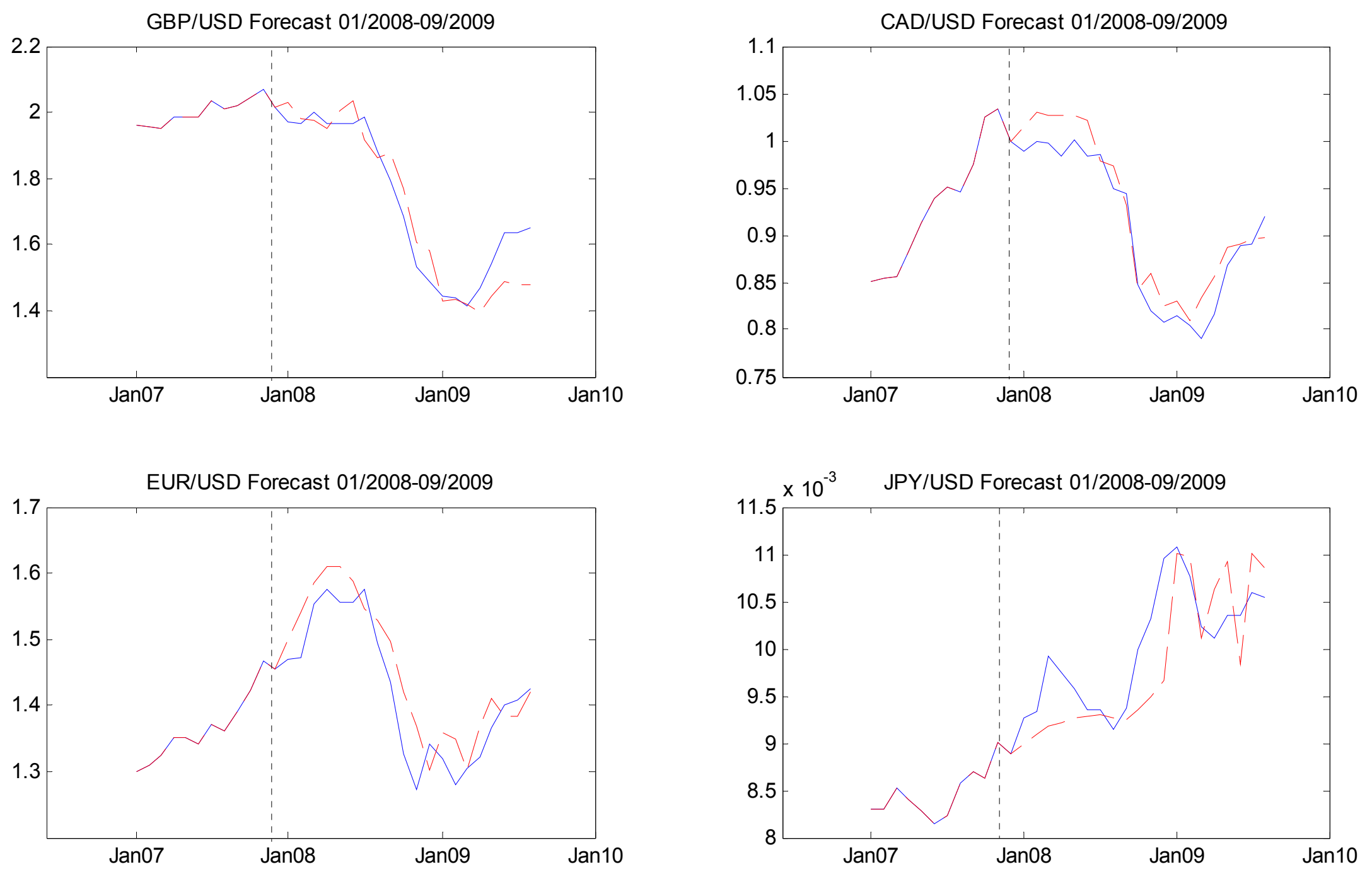